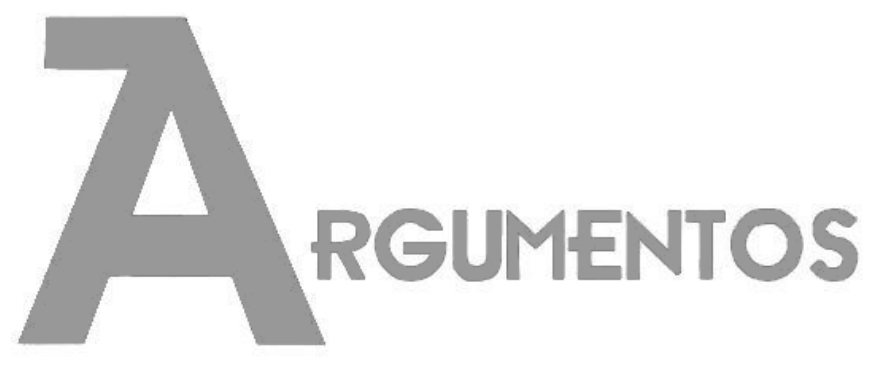

Vol. 17, n. 2, jul./dez. 2020 ISSN: 2527-2551 (online)

\title{
Institucionalización del Congreso Federal Mexicano. Transición democrática y cambio organizacional
}

Laura Valencia Escamilla ${ }^{1}$

Recebido em: 08/02/2020

Aprovado em: 05/06/2020

Resumen: En el documento se identifica cinco modelos de desarrollo del Congreso en México con base en el desarrollo y consolidación democráticas por un lado, y por el otro la transformación del proceso de institucionalización de la instancia representativa en el país. Las etapas por las que transita la propia organización parlamentaria son abordadas a partir del equilibrio entre poderes, el proceso de institucionalización de la estructura legislativa, la profesionalización de los órganos de decisión del Congreso y la introducción de esquemas de apertura parlamentaria. Mediante los procesos de integración del Congreso Mexicano, se abordará la composición legislativa de los grupos parlamentarios y la formación de mayorías; los cambios en las reglas del juego parlamentario en la revaloración de la estructura, organización y profesionalización del poder legislativo y el efecto de la introducción de mecanismos de transparencia y la rendición de cuentas en la relación entre representantes y representados a través de los diferentes sistemas de monitoreo y control ciudadano integrados a las nuevas tecnologías.

Palabras clave: Poder Legislativo, Institucionalización parlamentaria, Profesionalización legislativa, parlamento abierto, experiencia legislativa.

\section{Institucionalização do Congresso Federal Mexicano. Transição democrática e mudança organizacional}

Resumo: $\mathrm{O}$ documento identifica cinco modelos de desenvolvimento do Congresso no México, baseados no desenvolvimento e consolidação democráticos, por um lado, e por outro, na transformação do processo de institucionalização do órgão representativo no país. As etapas pelas quais a organização parlamentar viaja são abordadas a partir do equilíbrio entre poderes, do processo de institucionalização da estrutura legislativa, da profissionalização dos órgãos de decisão do Congresso e da introdução de esquemas de abertura parlamentar. Através dos

1 Profesora Investigadora del Departamento de Política y Cultura de la Universidad Autónoma Metropolitana, Unidad Xochimilco. Ciudad de México. E-mail: Ivalesc@correo.xoc.uam.mx. ORCID: 00000001-6592-3656. 
processos de integração do Congresso mexicano, será abordada a composição legislativa dos grupos parlamentares e a formação de maiorias; as mudanças nas regras do jogo parlamentar na reavaliação da estrutura, organização e profissionalização do poder legislativo e o efeito da introdução de mecanismos de transparência e responsabilidade nas relações entre representantes e representados pelos diferentes sistemas de monitoramento e controle de cidadãos integrados às novas tecnologias.

Palavras-chave: Poder Legislativo, Institucionalização Parlamentar, Profissionalização Legislativa, Parlamento Aberto, Experiência Legislativa.

\section{Institutionalization of the Mexican Federal Congress. Democratic transition and organizational change}

Abstract: The document identifies five development models of the Congress in Mexico based on democratic development and consolidation on the one hand, and on the other the transformation of the institutionalization process of the representative body in the country. The stages through which the parliamentary organization itself are approached from the balance between powers, the process of institutionalization of the legislative structure, the professionalization of the decision-making bodies of the Congress and the introduction of parliamentary opening schemes. Through the integration processes of the Mexican Congress, the legislative composition of parliamentary groups and the formation of majorities will be addressed; the changes in the rules of the parliamentary game in the revaluation of the structure, organization and professionalization of the legislative power and the effect of the introduction of transparency mechanisms and accountability in the relationship between representatives and represented through the different systems of citizen monitoring and control integrated to new technologies.

Keywords: Legislative Power, Parliamentary Institutionalization, Legislative Professionalization, Open Parliament, Legislative Experience.

\section{Introdução}

El poder legislativo, como pieza clave del sistema de representación política, se ha caracterizado por ser una institución en constante proceso de mutación ideológica y organizacional, cambios que han fluido del liberalismo oligárquico a la democracia moderna. Cuatro son los modelos que han caracterizado la transformación de la institución legislativa en este proceso de evolución, los tres primeros son descritos por García Morillo en su artículo Mitos y realidades del parlamentarismo (1991: 120-121), y el último se propone a partir de nuevos fenómenos adicionales a las democracias representativas: la participación ciudadana y la tecnificación de las actividades legislativas.

El primer tipo denominado "parlamentarismo salvaje" es resultado de la crítica a la soberanía parlamentaria, caracterizado por la ausencia de organizaciones políticas capaces de alcanzar una mayoría estable, indisciplina interna de la mayor parte de las organizaciones políticas y supeditación del Ejecutivo al Legislativo, particularidades 
Artigo | Institucionalización del Congreso Federal Mexicano. Transición democrática y cambio organizacional (ESCAMILLA, Laura Valencia)

propias del primer tercio del siglo XX. Este tipo de gobierno representativo se percibe por la crónica inestabilidad gubernamental, y la polarización e irracionalidad del debate político. Ejemplo de ello, lo representan la III República francesa, la República de Weimar y la II República española.

El segundo modelo denominado "parlamentarismo racionalizado" surge por el fracaso de las experiencias de los primeros gobiernos representativos y su crónica inestabilidad. Los constitucionalistas posteriores a la segunda guerra mundial, intentaron corregir al máximo los defectos de aquella primera experiencia, mediante la racionalización de la vida parlamentaria en la que se pretende reflexionar sobre las reglas que aseguraren la estabilidad gubernamental e impidan vacíos de poder, mecanismos de control parlamentario y exigencias de responsabilidad de parte del Ejecutivo. Esta etapa se inaugura con la Ley de Bonn en los años cincuenta del siglo XX y la introducción de la moción de censura constructiva que varios países europeos adoptarían para darle mayor estabilidad a sus asambleas parlamentarias.

El tercer tipo denominado "parlamentarismo estructural" propio de la década de los años ochenta del siglo XX, introduce la función legislativa, además del control y la responsabilidad política del modelo anterior, se suma la organización interna de la vida parlamentaria cuyo fin es: estructurar el debate acorde con la planificación estatal, la capacidad presupuestal del órgano legislativo y su relación con la sociedad civil cada vez más demandante ante la introducción de mecanismos de participación semidirecta en las decisiones políticas, (VIRGALA, 1995).

Por último, la introducción de nuevas tecnologías a la actividad estatal ha producido la generación de un nuevo modelo denominado "parlamentarismo abierto" el cual solo es posible bajo los cánones de racionalización y estructuración de la institución legislativa. Es decir, plena división de poderes, representación efectiva, y funcionalidad legislativa. Esta etapa se inaugura a la entrada del siglo XXI, en la perspectiva de avanzar en la transparencia, la innovación tecnológica, la rendición de cuentas y el control ciudadano.

Bajo este nuevo paradigma se propone abordar el proceso de institucionalización y transformación del Poder Legislativo mexicano expresado en dos sentidos: los cambios (exógenos) promovidos por las transformaciones políticas del país y sus efectos en la conformación de la asamblea parlamentaria, por un lado; y la propia evolución 
Artigo | Institucionalización del Congreso Federal Mexicano. Transición democrática y cambio organizacional (ESCAMILLA, Laura Valencia)

(endógena) del Congreso mexicano dentro de un proceso de institucionalización, reorganización y profesionalización de la labor legislativa.

Se puede decir que el Congreso mexicano ha incursionado en los cuatro modelos de parlamentarismo arriba referidos. Si bien es cierto no se identifican como un proceso ascendente, podemos afirmar que la institución representativa ha transitado por cada uno de ellos, a veces de manera inconclusa (parlamentarismo estructurado y abierto) y en otras ocasiones, el tránsito ha sido retroactivo e intermitente (parlamentarismo salvaje y racionalizado).

\section{Transición democrática y cambio Institucional}

El arribo democrático a la región latinoamericana ha provocado la transformación de diversas instituciones, particularmente las de corte democrático como los sistemas electorales, de partidos, así como las instituciones representativas a través de procesos de modernización institucional, organizacional, de gestión y tecnológica.

En el caso de los congresos, el interés por transformarlos no solo consistió en la activación de los mismos, sino en devolver a la institución el control político, fiscal y de gobierno, además de ampliar la base representativa a fin de contribuir con las expectativas ciudadanas de gozar de una democracia que acercara la representación nacional a una ciudadanía incrédula de gobiernos autoritarios, ineficientes y corruptos.

El proceso de transformación institucional en la region ha variado de país en país, pero en general se puede decir que el fenómeno democrático ha sido un proceso histórico diferenciado cuyas peculiaridades se relacionan con la profundidad de los procesos de consolidación. Las marcadas diferencias han sido señaladas en torno a la durabilidad y estabilidad de las democracias (HUNTINGTON 1996; COLOMER, 2001|); a la fase histórica en la que ocurrió el proceso democrático (LINZ, 1988), y al grado de consolidación institucional y resistencia al cambio (MORLINO 1998; DAHL, 2006), entre las aportaciones más importantes. Todos estos procesos intentan explicar las causas que llevaron a muchos países a consolidar o no sus democracias.

Hoy, las tareas pendientes para América latina y para México en particular se han orientado hacia la consolidación y profundización de las incipientes democracias. Se ha 
Artigo | Institucionalización del Congreso Federal Mexicano. Transición democrática y cambio organizacional (ESCAMILLA, Laura Valencia)

hecho evidente que por la debilidad institucional de muchas de estas democracias, no ha sido posible avanzar en la modernización de las economías y las sociedades de estos países, pero ¿cuáles son las causas de dicha "debilidad"?

Morlino (1986) identifica dos etapas posteriores a la transición: instauración y consolidación. La consolidación se identifica con la fase de reforzamiento del sistema democrático al aumentar la estabilidad y persistencia que contrarresta los posteriores momentos de crisis. Por su parte, la instauración es el período de creación o diseño de nuevas instituciones y procedimientos democráticos.

En esta etapa - de instauración - Cansino (2004) señala dos componentes adicionales del proceso: la destitución del antiguo régimen y el nuevo diseño constitucional. En el diseño, se busca derogar aquellas normas jurídicas existentes en el régimen autoritario con la creación de nuevas constituciones o la transformación de reformas profundas de la constitución existente, lo que incrementa el potencial de persistencia del nuevo régimen democrático y lo conduce a su consolidación. La carencia de alguno de los dos elementos sugiere la proclividad hacia la debilidad institucional, dado que los nuevos regímenes enfrentan problemas de consolidación y por tanto, el afianzamiento democrático es más susceptible frente a las crisis que pueden devenir en descrédito de los nuevos sistemas.

En la actualidad, los países más susceptibles a los problemas de consolidación e instauración son aquellas democracias provenientes de regímenes autoritarios de partido único o cuasi único (MAGALONI, 2006) en donde su perdurabilidad depende de la asimetría de recursos; de una competencia electoral tenue y una oposición débil incapaz de iniciar el proceso de instauración. El resultado es un bajo afianzamiento institucional.

Se puede decir en términos muy generales que la transición en México la podemos caracterizar a partir de cinco elementos:

- $\quad$ Se trata de una "transición prolongada" en la que se produce más que una liberalización y posterior democratización, una descompresión autoritaria cuya apertura se da a través de la celebración de elecciones, siempre de manera controlada (CASPER, 2001).

La transformación del régimen ha sido el resultado de un largo proceso de construcción de corte democrático caracterizado por un "cambio sin 
Artigo | Institucionalización del Congreso Federal Mexicano. Transición democrática y cambio organizacional (ESCAMILLA, Laura Valencia)

ruptura en el orden institucional establecido" (ELIZONDO y NACIF, 2002).

La transición política no se basó en pactos que irrumpen desde el pasado y producen transformaciones político-institucionales, sino en una permanente negociación denominada: "transición votada", ya que los cambios se llevan a cabo mediante el sistema electoral y de partidos (MERINO, 2003).

- $\quad$ El promotor de los cambios en la construcción institucional se da bajo el liderazgo del partido dominante (MAGALONI, 2006).

Y por tanto, la oposición enfrenta los procesos de competencia bajo una postura de desventaja asimétrica reforzada por la fuerza del partido dominante (MAGALONI, 2006).

El conjunto de estos planteamientos sobre la transición mexicana, nos lleva a suponer que se trata de un proceso inconcluso en donde surgen dudas sobre el tipo de instituciones representativas en las que se finca la democracia mexicana, ¿si la transición en México no fue consecuencia de una ruptura institucional con su pasado autoritario, es posible que estemos hablando de las bases del diseño de una nueva institucionalidad?

Dado que el ingreso del contingente opositor en México surgió por la vía electoral más que por la movilización, es posible afirmar que ¿el Poder Legislativo mexicano como escenario del intercambio entre las diferentes fuerzas políticas, cumple por un lado con la función de ser creador de su propia institucionalización -como el proceso mediante el cual un congreso pasivo o caracterizado por ser un rubber stamps (sello de goma) llega a convertirse en una institución autónoma, política y técnicamente capacitada y con influencia en las políticas?; y al mismo tiempo ¿convertirse en el constructor de las reformas constitucionales en las que se busca no solo legitimar el actual sistema, sino establecer pactos que instauren, consoliden y mantengan la actual democracia que por momentos es cuestionada?

\section{Bases para la institucionalización de los poderes legislativos}

Actualmente, los procesos de modernización estatal expresados fundamentalmente en las reformas de los aparatos administrativos, en la descentralización política y la consolidación democrática, han redefinido las diversas 
concepciones del Estado y su aparato institucional. En este ejercicio, la figura uno muestra como el Poder Legislativo mexicano se ha redefinido en su relación con los otros dos poderes a fin de contribuir a otorgar mayores equilibrios, que se traducen en el reforzamiento de la autonomía parlamentaria (respecto al poder Ejecutivo y al poder Judicial u otros poderes fácticos, como el ejército, las empresas, etcétera); a la institucionalización de la organización legislativa (reforzamiento estructural y racional de la organización); a la incorporación del poder legislativo en los procesos de la función pública (gestión, agenda, presupuesto y formulación de políticas públicas); a la dinámica de transformación respecto a la nueva relación con la sociedad civil a través de la participación ciudadana y sus mecanismos institucionales (referéndum, plebiscito, iniciativa popular); así como a la intervención y control directo de los ciudadanos en las decisiones públicas, mediante los procesos de democratización de la función parlamentaria (acceso a la información, transparencia, rendición de cuentas, consultas públicas, y parlamento abierto).

Figura 1. Bases para la Institucionalización y Modernización del Poder Legislativo mexicano

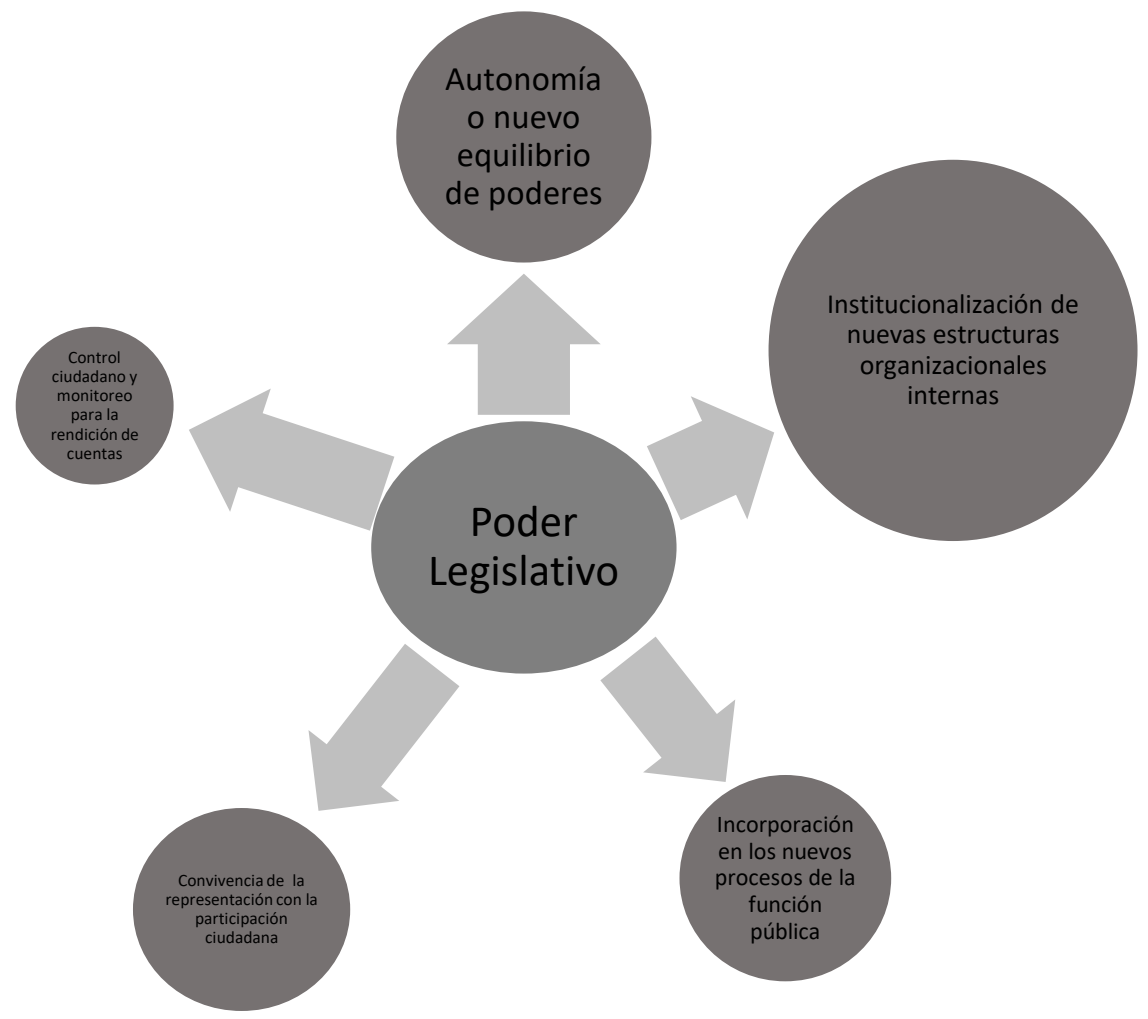
dimensión.

Elaboración Propia. Los círculos son dispares dada la variabilidad del cambio sufrido en cada 
Artigo | Institucionalización del Congreso Federal Mexicano. Transición democrática y cambio organizacional (ESCAMILLA, Laura Valencia)

\subsection{Autonomía o nuevo equilibrio de poderes}

La experiencia mexicana respecto a la institucionalización y modernización de su Poder Legislativo se puede observar como un proceso constante $y$, por momentos intermitente, que ha ido de la mano de la transición democrática caracterizada por procesos político-institucionales, donde los cambios se han llevado a cabo mediante la transformación del sistema electoral y de partidos (MERINO, 2003), así como de la propia consolidación de la organización legislativa que va de la dependencia y aprobación automática (situación que pervivió durante la larga hegemonía del Partido Revolucionario Institucional, por poco más de setenta años), pasando por la formación estructural y el obstruccionismo irracional propio del parlamentarismo salvaje (en el periodo de la alternancia con el Partido Acción Nacional al frente del gobierno), al actual modelo de construcción y consolidación institucional del poder legislativo mexicano que da inicio en los años noventa y que aún se mantiene inconcluso y por momentos estático (DÍAZ, 2000; SAIEGH, 2010).

La actual transformación del sistema electoral y de partidos en la conformación e institucionalización del Poder Legislativo mexicano pasa por dos momentos en la formación de los gobiernos contemporáneos: los de mayoría o unificados y los divididos. El primero se localiza entre 1988 y 1997 y se caracteriza por: el dominio del Partido Revolucionario Institucional (PRI) quien ocupó el Ejecutivo y controló al Poder Legislativo como herramienta ratificadora de las decisiones del presidente en turno; baja capacidad técnica y política; ausencia de mecanismos institucionales de interacción con la sociedad civil; y manejo del Congreso bajo criterios patrimonialistas sin ningún apego técnico en manos del partido dominante.

El segundo momento se refiere a la formación de gobiernos divididos o no mayoritarios $^{2}$ que inicia en 1997 y se consolida en el año 2000, al ascenso de los gobierno

\footnotetext{
${ }^{2}$ Los gobiernos divididos o sin mayoría se caracterizan por tener un presidente que pertenece a un partido y un poder legislativo con mayoría distinta al partido del presidente o, por aquellos gobiernos donde el grado de fragmentación es tal que es posible identificar tres escenarios: gobiernos unipartidarios con una mayoría parlamentaria contraria al partido del presidente, o gobiernos con fuerzas políticas desiguales en tamaño, a favor de una de ellas, en esta situación se incrementa el riesgo de bloqueo y conflicto; gobiernos minoritarios donde ningún partido ostenta la mayoría, en este caso particular la negociación de acuerdos parlamentarios es puntual y provisional y supeditada a la proximidad de los partidos en las políticas concretas y; gobiernos de coalición con fuerzas políticas similares en tamaño donde la
} 
Artigo | Institucionalización del Congreso Federal Mexicano. Transición democrática y cambio organizacional (ESCAMILLA, Laura Valencia)

del partido de centro derecha Acción Nacional (PAN), y es producto de las diversas reformas electorales que conformaron un sistema electoral multipartidista, mixto y competitivo, donde el Ejecutivo ha pertenecido a un partido y el Poder Legislativo Federal ha estado fragmentado entre las distintas fuerzas ganadoras, pero con el predominio de dos partidos o coaliciones (el gobernante PAN y el ahora opositor PRI). Dicha pluralidad ha dado paso al proceso de institucionalización legislativo desde su incipiente formación hasta el proceso de consolidación que aún sigue en marcha.

Como se observa en la gráfica uno, el sistema de partidos ha tenido una evolución diversa y dispersa; para empezar, la fragmentación ha sido limitada: dos han sido los partidos con peso real en la formación de mayorías (PRI y PAN) y la izquierda ha estado presente de manera intermitente y fragmentada (inicialmente con el Partido de la Revolución Democrática o PRD y después de un desmembramiento de la izquierda surge MORENA o Movimiento de Regeneración Nacional). En segundo término, las fuerzas partidistas no han sido similares en tamaño y, por tanto, la capacidad negociadora del partido del presidente con la oposición ha variado y depende del tamaño de los grupos. Durante los gobiernos sin mayoría, el Ejecutivo no siempre controló al Congreso; sobre todo, en los gobiernos panistas (2000-2012), cuyo dominio lo ostentó el bloque partidista del régimen anterior PRI. De esta manera, el Revolucionario Institucional, se convirtió en el partido dominante entre 2000 y 2012, mientras que el PAN y en mucha menor medida el PRD en dos partidos con pesos relativos. En el periodo de 2012 al 2018, la coalición del PRI y el minoritario Partido Verde Ecologista de México (PVEM) -sobretodo el primero- dominaron el escenario legislativo al conseguir en conjunto el 49 y $47 \%$ de las bancadas en ambas cámaras de representación.

Sin embargo, a diferencia de los gobiernos mayoritarios con partido único, la oposición en esta etapa del PRI es una oposición más equilibrada respecto al grupo mayoritario, de ahí que la composición del Congreso en 2018 con la alternancia mayoritaria del grupo de izquierda mantiene la lógica de coalición y equilibrio entre el grupo mayoritario que soporta las decisiones del presidente y la coalición opositora ahora conformada por el PAN, el PRD y Movimiento Ciudadano (MC).

negociación y el acuerdo es estable, cuya duración depende de la celebración de las siguientes elecciones (RENIU, 2008). 
Artigo | Institucionalización del Congreso Federal Mexicano. Transición democrática y cambio organizacional (ESCAMILLA, Laura Valencia)

Gráfica 1. Contracción y Dispersión del poder en gobiernos mayoritarios y sin Mayoría (1988-

2021)
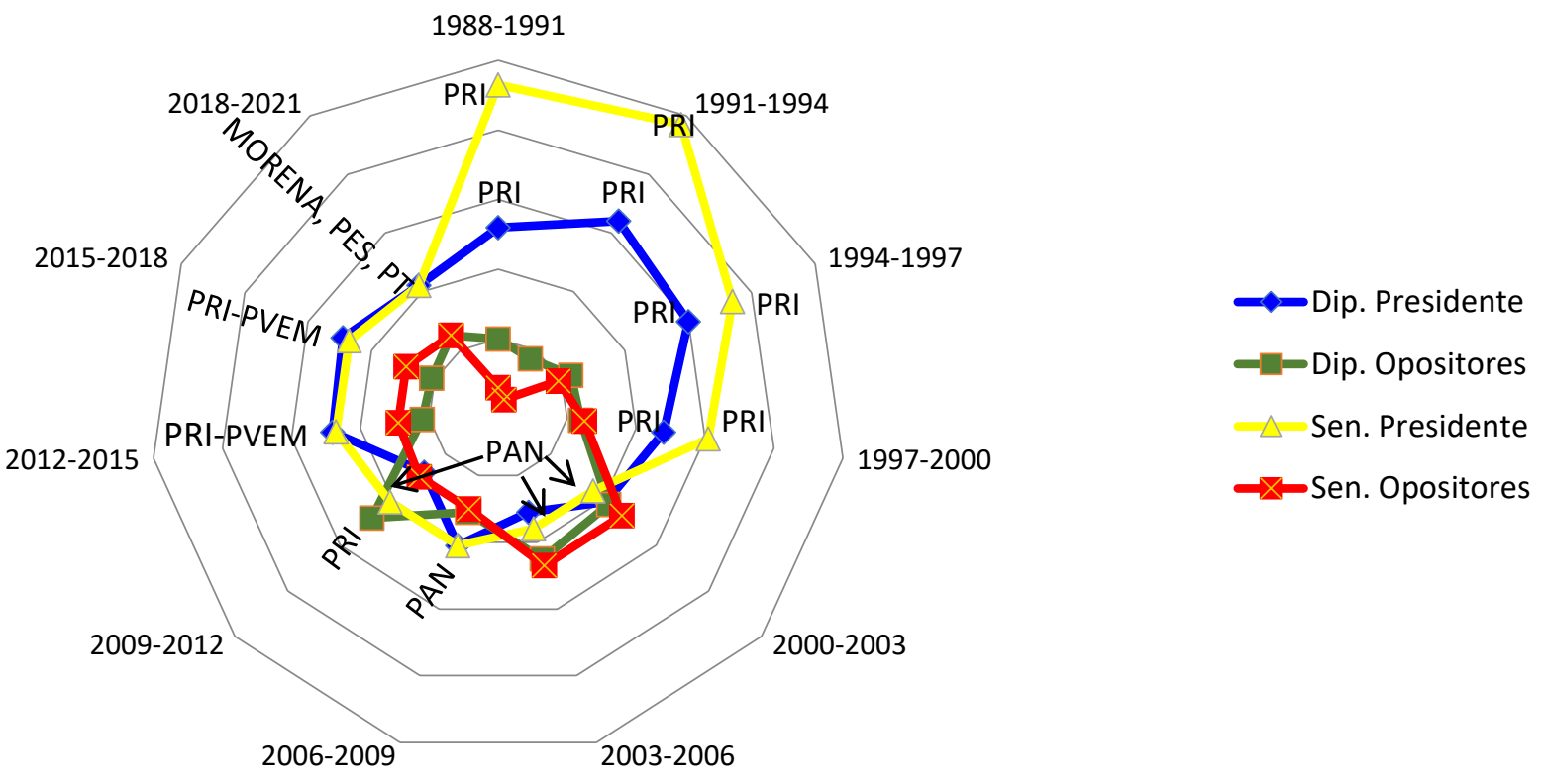

Cuadro 1. Contracción y Dispersión del poder en gobiernos mayoritarios y sin Mayoría (1988-2021) (continuación)

\begin{tabular}{|c|c|c|c|c|}
\hline $\begin{array}{l}\text { Composición de las } \\
\text { legislaturas }\end{array}$ & $\begin{array}{l}\% \text { de diputados del } \\
\text { partido o coalición del } \\
\text { presidente* }\end{array}$ & $\begin{array}{l}\% \text { de diputados del } \\
\text { partido opositor }\end{array}$ & $\begin{array}{l}\% \text { de senadores } \\
\text { partido o coalición } \\
\text { presidente } \\
\text { pr* }^{* *}\end{array}$ & $\begin{array}{l}\% \text { de Senadores del } \\
\text { partido opositor }\end{array}$ \\
\hline \multicolumn{5}{|c|}{ Gobiernos Mayoritarios con partido único. Presidentes: Carlos Salinas de Gortari (PRI 88-94); Ernesto Zedillo (PRI 94-2000) } \\
\hline 1988-1991 & $52 \%(\mathrm{PRI})$ & $20.2 \%(\mathrm{PAN})$ & $93 \%$ (PRI) & $6.25 \%(\mathrm{PMS})$ \\
\hline 1991-1994 & $64 \%$ (PRI) & $17.8 \%(\mathrm{PAN})$ & $97 \%$ (PRI) & $3.1 \%(\mathrm{PMS})$ \\
\hline 1994-1997 & $60 \%(\mathrm{PRI})$ & $23.8 \%(\mathrm{PAN})$ & $74 \%(\mathrm{PRI})$ & $19.5 \%(\mathrm{PAN})$ \\
\hline \multicolumn{5}{|c|}{ Gobiernos sin Mayoría. Presidentes: Vicente Fox (PAN 2000-2006); Felipe Calderón (PAN 2006-2012) } \\
\hline $1997-2000$ & $48 \%$ (PRI) & $24.2 \%(\mathrm{PAN})$ & $60 \%$ (PRI) & $25.7 \%(\mathrm{PAN})$ \\
\hline $2000-2003$ & $41 \%(\mathrm{PAN})$ & $42 \%$ (PRI) & $36 \%(\mathrm{PAN})$ & $47 \%$ (PRI) \\
\hline $2003-2006$ & $30 \%(\mathrm{PAN})$ & $45 \%$ (PRI) & $36 \%(\mathrm{PAN})$ & $47 \%$ (PRI) \\
\hline $2006-2009$ & $41 \%(\mathrm{PAN})$ & $31.4 \%(\mathrm{PRD})$ & $40 \%(\mathrm{PAN})$ & $30 \%$ (PRI) \\
\hline $2009-2012$ & $28.6 \%(\mathrm{PAN})$ & $48 \%$ (PRI) & $40 \%$ (PAN) & $30 \%$ (PRI) \\
\hline \multicolumn{5}{|c|}{$\begin{array}{l}\text { Gobiernos Mayoritarios con coalición dominante. Presidentes: Enrique Peña Nieto (PRI 2012-2018); Andrés Manuel López Obrador } \\
\text { (MORENA 2018-2024) }\end{array}$} \\
\hline $2012-2015$ & $48.2 \%$ (PRI-PVEM) & $22.8 \%(\mathrm{PAN})$ & $47.6 \%$ (PRI-PVEM) & $29.7 \%(\mathrm{PAN})$ \\
\hline $2015-2018$ & 49\% (PRI-PVEM) & $21.8 \%(\mathrm{PAN})$ & $47.6 \%$ (PRI-PVEM) & $29.7 \%(\mathrm{PAN})$ \\
\hline $2018-2021$ & $\begin{array}{l}42 \% \text { (MORENA, PT, } \\
\text { PES) }\end{array}$ & $25.7 \%$ (PAN, PRD, MC) & $\begin{array}{lll}42 \% & \text { (MORENA, } \\
\text { PES) } & \end{array}$ & $25 \%$ (PAN, PRD, MC) \\
\hline $\begin{array}{l}\text { Elaboración pre } \\
\text { * La Cámara de } \\
\text { ** De } 1988 \text { a } 1 \\
\text { PRI = Partido R } \\
\text { PAN = Partido } \\
\text { PVEM = Partido } \\
\text { PRD = Partido c } \\
\text { MORENA = Mo } \\
\text { PT = Partido de } \\
\text { PES = Partido E }\end{array}$ & $\begin{array}{l}\text { ia con base en datos del II } \\
\text { iputados se compone de } 5 \\
94 \text {, el total de Senadores e } \\
\text { volucionario Institucional } \\
\text { cción Nacional } \\
\text { Verde Ecologista de Méxic } \\
\text { la Revolución Democrátic } \\
\text { imiento de Regeneración } \\
\text { Trabajo } \\
\text { cuentro Social }\end{array}$ & $\begin{array}{l}\text { FOPAL (2020) } \\
0 \text { legisladores } \\
\text { de } 64 ; \text { de } 1994 \text { en adelan }\end{array}$ & la CS se integra por 128 leg & sladores. \\
\hline
\end{tabular}


Artigo | Institucionalización del Congreso Federal Mexicano. Transición democrática y cambio organizacional (ESCAMILLA, Laura Valencia)

Es decir, en la etapa de gobiernos mayoritarios (1988-1997), la hegemonía del PRI en el gobierno, le restó peso a los partidos de oposición, lo que ocasionó un sistema unipartidario con una o dos fuerzas opositoras sin contrapeso en la agenda legislativa. En gobiernos sin mayoría (2000-2012) la tendencia ha sido más bien bipartidista en la etapa del 2000 al 2009 donde gobernaron Vicente Fox y Felipe Calderón durante su primer trienio, ambos gobiernos de centro derecha. Posterior a 2009, el comportamiento del sistema de partidos fue tripartidista, con dominio del Partido Revolucionario Institucional como opositor hasta el 2012 que regresa nuevamente al poder, pero bajo otro escenario.

Al regreso del PRI en 2012, encabezado por Enrique Peña Nieto, las coaliciones se formaron con dos o más partidos tanto del lado del PRI como de la izquierda PRD, MORENA, PT, MC, PES y recientemente en 2018, la derecha también se suma a la competencia mediante coaliciones (PAN y $\mathrm{MC}$ ), situación que no necesariamente garantiza una agenda legislativa en común.

Como puede observar el lector, en el cuadro anterior, el PRI en el gobierno (19882000) o en la oposición (2000-2012) ostentó hasta 2018 la primera fuerza política del Congreso en ambas cámaras, -salvo en 2006 en la cámara baja cuando el PRD, por primera vez, fue la segunda fuerza. Es decir, el PRI, en la etapa de gobiernos no mayoritarios, se mantuvo como el partido predominante dado que había sido la primera fuerza legislativa al obtener en promedio $48 \%$ de curules, -ya sea solo o en coalición-, en ambas cámaras. Esto significa que el control de la agenda legislativa continuó en manos del Revolucionario Institucional, aun estando en la oposición, por lo que las preguntas que saltan a la vista son ¿cuál ha sido el efecto del control legislativo en manos del PRI?; ¿el dominio de este partido permitió la emancipación del Poder Legislativo?, ¿fue posible construir acuerdos para instaurar la institucionalización del Congreso mexicano?, ¿si los autoritarios se convirtieron en reformadores, qué tan profundas y aceleradas fueron las reformas institucionales?

Empecemos por evaluar el peso de cada una de las fuerzas parlamentarias en la toma de decisiones legislativas y la importancia de la oposición en ambas cámaras. A partir del índice de oposición efectiva del cuadro dos nos podemos percatar que el dominio de la oposición sólo se observa cuando el partido que la compone es el PRI, no solo por su tamaño, sino por la cohesión que logra tener como partido, a diferencia del 
Artigo | Institucionalización del Congreso Federal Mexicano. Transición democrática y cambio organizacional (ESCAMILLA, Laura Valencia)

PRD y el peso de sus facciones internas o incluso del PAN en momentos de disidencia frente a cooperar o no con el PRI. Por el contrario, la importancia de la oposición disminuye cuando el PRI está en el poder, ni el PAN, y sobretodo, el PRD han logrado hasta antes de 2018 mantener un peso significativo para influir en la agenda gubernamental y legislativa. Posterior a las elecciones de 2018, el potencial electoral de PRI se revierte a favor de MORENA y su coalición. En ambos escenarios, la constante es que en la medida en la que el PRI como partido opositor o partido en el poder, ocupó la primera mayoría, su poder político y control sobre la agenda fue contundente hasta 2018. En adelante, MORENA se percibe como la siguiente fuerza política con peso real en la aprobación de la agenda legislativa. Sin embargo, como se aprecia en el cuadro siguiente, los partidos opositores al grupo mayoritario han ido manteniendo cierto equilibrio respecto al partido o a la coalición mayoritaria en el Congreso federal.

\section{Cuadro 2. Índice de partido dominante e índice de oposición efectiva ${ }^{3}$}

\footnotetext{
${ }^{3}$ El índice de partido dominante es una medida que se obtiene en términos del peso efectivo de este en función de la fragmentación electoral por un lado, el tamaño del dominio legislativo y el peso de la oposición por el otro. Molinar (1991) contribuyó con un índice que revalora dentro del multipartidismo, al partido ganador y su peso real respecto a los pequeños partidos, es decir, se trata de captar la capacidad negociadora de los mismos -que se reduce o se incrementa en la medida en la que el partido dominante revela la distribución real de las mayorías en el Congreso. Si bien al aplicar el clásico índice de LAAKSO y TAAGEPERA (1979) el número efectivo de partidos en México ha oscilado entre 2.5 y 3.3; cuando aplicamos el índice de partido dominante, la fragmentación al interior del Congreso se reduce de un sistema tripartidista a uno bipartidista y ha llegado a ser unipartidista dado el peso de los partidos en las decisiones legislativas que requieren de mayorías absolutas (para aprobar legislación secundaria) y/o mayorías calificadas (para aprobar reformas constitucionales). La propuesta de Molinar (1991) para medir el peso del partido dominante es la siguiente: $N P=1+N^{2} \sum^{n}{ }_{1=2} p_{i} 2$ Donde el número de partidos NP es igual a uno más el producto de la multiplicación de $\mathrm{N}$ (Número efectivo de partidos) al cuadrado por la sumatoria de los porcentajes de votos o escaños al cuadrado a partir del segundo partido más votado. Este método integra la fragmentación y el peso real del partido dominante (VALENCIA, 2013). Para obtener el índice de oposición efectiva (IOE) se pondera el promedio de la magnitud de los partidos de oposición (O) sobre el promedio de la magnitud del partido o la coalición que apoya al presidente. IEO= O/G; donde para obtener $\mathrm{O}$ se pondera el porcentaje de escaños a favor de los partidos opositores más grandes. La fórmula es: $\mathrm{O}=\sum \mathrm{oi}^{2} / \Sigma \mathrm{oi}$; donde oi es la proporción de escaños controlados por el partido en la oposición. El resultado del índice maneja valores entre 0 y 1 , cuando el tamaño del partido de oposición no es sustantivo el valor es cercano a 0 , y por el contrario, cuando el peso es sustantivo el valor es cercano o por encima de uno. $\mathrm{G}=\Sigma \mathrm{gi}^{2} / \Sigma \mathrm{gi}$; donde $\mathrm{G}$ es igual al partido del presidente y gi es la proporción de bancas controladas por el partido presidencial, cuando los resultados obtenidos estén cercanos o igual a 0 significa que el presidente controla la legislatura, cuando el resultado es cercano o por encima de uno, nos indica que la oposición tiene el mismo tamaño legislativo que el partido gobernante. (JIMÉNEZ, 2006 p. 150-151).
} 
Artigo | Institucionalización del Congreso Federal Mexicano. Transición democrática y cambio organizacional (ESCAMILLA, Laura Valencia)

\begin{tabular}{|l|l|l|l|l|ll|ll|}
\hline $\begin{array}{l}\text { Trienios en } \\
\text { gobiernos sin } \\
\text { mayoría }\end{array}$ & $\begin{array}{l}\text { NEP: número efectivo } \\
\text { de partidos y } \\
\text { NP: índice de partido } \\
\text { Dominante } \\
\text { Diputados }\end{array}$ & $\begin{array}{l}\text { NEP: número efectivo de } \\
\text { partidos y } \\
\text { NP: índice de partido } \\
\text { Dominante } \\
\text { Senadores }\end{array}$ & $\begin{array}{l}\text { Índice de oposición } \\
\text { Efectiva Diputados } \\
\text { (IOE) }\end{array}$ & $\begin{array}{l}\text { Índice de oposición } \\
\text { Efectiva Senadores } \\
\text { (IOE) }\end{array}$ \\
\hline $1997-2000$ & 2.93 & 2.03 & 2.3 & 1.1 & $0.42 \quad$ (SPD) & 0.40 & (SPD) \\
\hline $2000-2003$ & 2.81 & 2.41 & 2.7 & 2.0 & $1.02 \quad$ (PRI) & 1.39 & (PRI) \\
\hline $2003-2006$ & 3.05 & 2.18 & 2.7 & 2.0 & $1.46 \quad$ (PRI) & 1.39 & (PRI) \\
\hline $2006-2009$ & 3.60 & 2.91 & 3.3 & 2.4 & $0.74 \quad$ (PRD) & 0.75 & (PRI) \\
\hline $2009-2012$ & 3.01 & 1.91 & 3.3 & 2.4 & 1.88 (PRI) & 0.75 & (PRI) \\
\hline $2012-2015$ & 3.16 & 1.82 & 3.1 & 1.2 & 0.38 (SPD) & 0.25 & (SPD) \\
\hline $2015-2018$ & 3.26 & 1.7 & 3.1 & 1.2 & 0.40 (SPD) & 0.25 & (SPD) \\
\hline
\end{tabular}

Elaboración propia con base en Molinar (1991) y Jiménez (2006).

Por otro lado, llama la atención que salvo el 2006, el PAN siempre se ha mantenido como segunda fuerza -independientemente de si está o no en el poder- lo que ha ocasionado dos compartimientos en el partido. Cuando es oposición, trata de influir en la agenda cooperando o apoyando el planteamiento gubernamental del Partido Revolucionario Institucional (situación que ha provocado conflictos y divisiones internas).

En cambio, cuando Acción Nacional ocupó la presidencia, su capacidad para formar alianzas fue limitada dado que el PRI -como partido opositor y al mismo tiempo partido dominante-, lejos de ser cooperativo, dificultó la oportunidad de conciliar una agenda entre ambos grupos. Esta situación devino en un bipartidismo polarizante durante la presidencia de Vicente Fox Quezada en su segundo trienio y en la administración de Felipe Calderón Hinojosa en la segunda parte de su mandato.

Por su parte, la izquierda, hasta 2015 había mantenido un peso relativamente reducido que sobresale en 2006 gracias a la fuerza de su candidato presidencial -Andrés Manuel López Obrador-, el partido logra ocupar la segunda posición en la cámara baja, no así en la de senadores donde el PRI se mantuvo como segundo grupo legislativo. Es decir, la izquierda como oposición, hasta antes de 2018, había estado un tanto marginada dado su reducido peso electoral, situación que ha llevado a los integrantes del grupo parlamentario a mantener un comportamiento no cooperativo y carente de cohesión interna ocasionado por el peso de las facciones y los objetivos particulares de estas. Sin embargo, esta postura de no cooperación los ha segregado de la mayoría de las decisiones públicas, además de causar diferentes divisiones internas. 
Artigo | Institucionalización del Congreso Federal Mexicano. Transición democrática y cambio organizacional (ESCAMILLA, Laura Valencia)

Al respecto, el debate al interior del PRD, partido de centro izquierda, ha virado de la no colaboración con los gobiernos en turno (entre 1991 fecha de su fundación al año 2000) a las alianzas electorales (inicialmente con partidos de izquierda), hacia la formación de coaliciones con el partido de centro derecha Acción Nacional (sobre todo a nivel subnacional desde el año 2000), Esta discusión interna les acarreó rupturas entre las diferentes facciones como la salida de importantes dirigentes como, por ejemplo, su fundador y líder moral Cuauhtémoc Cárdenas Solórzano (en 2014), así como su líder carismático Andrés Manuel López Obrador (en 2015) quien, apoyado por un movimiento político social (Movimiento de Regeneración Nacional o MORENA), alcanzó mucha mayor proyección que acompañado de la institucionalización partidista. Ambas disoluciones, sobre todo la última, los llevó a una profunda crisis y posible desaparición, si no mantenían una postura abierta al diálogo y alianzas con otros partidos, principalmente con Acción Nacional ante las elecciones de 2018 (ESPEJEL, 2012; ILLIADES, 2016).

Por otra parte, con el regreso del PRI al gobierno en 2012 en compañía de su coalición electoral (PVEM), obtuvo la ventaja, no solo en la elección presidencial, sino que el $48 \%$ de las bancadas del congreso fueron ocupadas por miembros de dicha alianza electoral, -porcentajes que ningún partido obtenía desde 1997 hasta ese momento-, lo que colocaba al partido del presidente y sus aliados como la primera fuerza política. Dicha situación abrió un escenario de oportunidad no solo para imponer una agenda de gobierno, sino para negociar una agenda legislativa acordada por el conjunto de las fuerzas políticas, dando paso al denominado Pacto por México. Para algunos autores el convenio entre las fuerzas políticas significó el inicio de un proceso de coalición parlamentaria destinada a negociar una agenda de temas compartidos, donde se acordaron los contenidos, los tiempos de debate y las reformas constitucionales a aprobar (ESCAMILLA, 2015). Si bien es cierto parecía que en ese momento el contexto favorecía la cooperación parlamentaria con el gobierno en turno, se debe mencionar que, dada la desproporción en el peso de las fuerzas políticas, la negociación no fue del todo equilibrada, como se demuestra en el cuadro dos.

De acuerdo con el índice del número de partidos efectivos del cuadro antes citado, tres son los partidos políticos con fuerza electoral. Sin embargo el dominio de la negociación estaba en el partido dominante, o más bien la coalición dominante 
Artigo | Institucionalización del Congreso Federal Mexicano. Transición democrática y cambio organizacional (ESCAMILLA, Laura Valencia)

encabezada por el PRI y el PVEM en ese momento, quienes en conjunto conformaron el grupo parlamentario mayoritario (con casi $50 \%$ de los votos) y un dominio partidista de 1.2 en el índice de partido dominante registrado en el cuadro dos, es decir, el peso real de la decisión la tenía la coalición del partido revolucionario institucional, dado que la oposición en ambas cámaras era tan reducida que no alcanzó ni el .50 del índice en el registro del peso de la oposición. Tanto en la cámara de diputados, pero sobre todo en la de senadores, el grupo opositor carecía de peso para incidir en las decisiones legislativas. De ahí que oponerse a la agenda programática del gobierno era inviable; por lo que optaron por negociar contribuciones a cambio de apoyar el paquete de reformas gubernamentales.

Durante este periodo (2012-2018) podemos observar que el efecto del desequilibrio entre la oposición (ampliamente fragmentada) y el dominio del grupo parlamentario mayoritario produjo la aprobación de ocho reformas constitucionales en un plazo relativamente corto de 18 meses, bajo una coalición sobredimensionada ${ }^{4}$ entre el PRI-PVEM, PAN Y PRD durante el primer año del gobierno de Enrique Peña Nieto, ${ }^{5}$ y el consentimiento del PRI y el PRD a favor de la reforma fiscal; y del PRI con el PAN en apoyo a la reforma política y energética. ${ }^{6}$ Si bien es cierto el soporte de las fuerzas políticas fue amplio y generoso para la aprobación del paquete de reformas, es importante apuntar que el Pacto por México originalmente se componía de 95 propuestas, de las cuales 65 fueron integradas a siete proyectos de ley que abarcaron las reformas: en materia de justicia penal; energética, hacendaria, educativa, laboral, financiera y político electoral. A pesar de la amplia aceptación de los proyectos, la agenda de los partidos de oposición no fue del todo integrada, por ejemplo, en el ámbito laboral, la seguridad social extendida, incremento salarial y la democracia interna de los

\footnotetext{
${ }^{4}$ Existen dos tipos de coaliciones parlamentarias: las coaliciones mínimas ganadoras con el número necesario de legisladores para aprobar legislación constitucional y/o secundaria; y las coaliciones sobredimensionadas como el conjunto de partidos que participan en la coalición más allá del número suficiente para aprobar legislación.

5 Las reformas apoyadas por todos los partidos cubren el tema educativo, telecomunicaciones, transparencia, finanzas, y endeudamiento de las entidades federativas. (CASTELLANOS, 2016).

${ }^{6}$ Por ejemplo, la reforma laboral y energética fueron las que menor respaldo consiguieron en la cámara baja, 351 y 354 votos respectivamente; la reforma educativa fue la de mayor consenso con 423 votos; la político electoral y la de telecomunicaciones así como la de competencia económica fueron respaldadas con 400 votos cada una. En el senado como colegisladora, dichas reformas tuvieron mayor consenso aún, la reforma laboral obtuvo 100 votos de 128, la de telecomunicaciones 113, de tal manera que, en promedio, las reformas obtuvieron el apoyo de 114 senadores de 128, lo que significa un apoyo sobredimensionado que potenció la legitimidad del gobierno hasta ese momento (INFOPAL, 2020).
} 
Artigo | Institucionalización del Congreso Federal Mexicano. Transición democrática y cambio organizacional (ESCAMILLA, Laura Valencia)

sindicatos no fueron temas que se añadieran a la propuesta final. En el ámbito político, el fuero, la segunda vuelta, el ministro de gabinete, fueron temas que, si bien no se excluyeron del todo de la iniciativa aprobada por los partidos en su conjunto, particularmente el fuero, aún continúan negociando su aprobación. Lo mismo sucedió con las reformas de leyes secundarias y algunos nombramientos provenientes de dichas reformas como la designación del fiscal.

Esto nos lleva a identificar a lo largo de los diferentes gobiernos dos escenarios dentro del Congreso mexicano: parálisis gubernamental cuando el partido dominante se encuentra en la oposición, y el partido en el gobierno es segunda fuerza, situación localizada en los segundos trienios de los gobiernos panistas; y disfuncionalidad legislativa (dado que las alianzas no son estables ni duraderas); cuando la oposición no mantiene el dominio, pero tampoco el partido en el gobierno, situación que le impide tomar decisiones gubernamentales a largo plazo o lo limita a cuestiones particulares, como en los primeros trienios de los gobiernos de Vicente Fox y Felipe Calderón, así como el segundo periodo de Enrique Peña Nieto.

\section{Transformación de la institucionalización de la estructura del Poder Legislativo} Mexicano

La apertura democrática permitió cuestionar el papel del Poder Legislativo mexicano a raíz del proceso de cambio del gobierno mayoritario en combinación con el partido hegemónico a gobiernos sin mayoría y partido dominante con alternancias, hasta llegar a gobiernos de mayoría coaligados. Este proceso a coadyuvado a la transformación del Congreso federal en México. De igual forma, se gestó la institucionalización del Congreso apoyado por los partidos políticos y sus grupos parlamentarios y la construcción de una estructura burocrática mediante la creación de espacios de expertos en cada una de las áreas a legislar donde buscan orientar a los grupos parlamentarios en la elaboración de iniciativas y en su propia discusión, a fin de racionalizar la discusión y el trabajo legislativo.

Coincidiendo con Díaz (2000) el Poder Legislativo en México pasó por diferentes etapas que dependían de la capacidad institucional y profesionalización de sus normas y personal que lo componen. En la figura dos se aprecia el proceso de apertura 
Artigo | Institucionalización del Congreso Federal Mexicano. Transición democrática y cambio organizacional (ESCAMILLA, Laura Valencia)

democrática con las etapas de transformación legislativa. Se ha transitado de un poder de aprobación automático con estructuras débiles que funcionaban más como herramientas de ratificación legal de los Ejecutivos en turno a un Congreso plural sin estructura normativa. Durante el proceso democrático, las etapas se clasifican en emergentes dentro del transcurso de la transición, de formación incipiente donde el desarrollo de la democratización se concluye e inicia la fase de institucionalización de la asamblea parlamentaria. Este proceso, convierte a la legislatura en una asamblea informada que a la vez inicia el proceso de transformación en dos sentidos, por un lado, la integración plural de sus miembros más interesados en el debate legislativo y en el trabajo interno, y por el otro, la nueva conformación organizacional y el ingreso de cuerpos técnicos profesionales y permanentes. En la medida en la que el proceso de tecnificación se consolida, la institucionalización más estructurada y racionalizada, al mismo tiempo, abre la pauta para el acceso ciudadano a la información, control y rendición de cuentas del propio poder legislativo, este último proceso aún es incipiente.

Figura 2. Etapas del Congreso mexicano por modelos de transformación

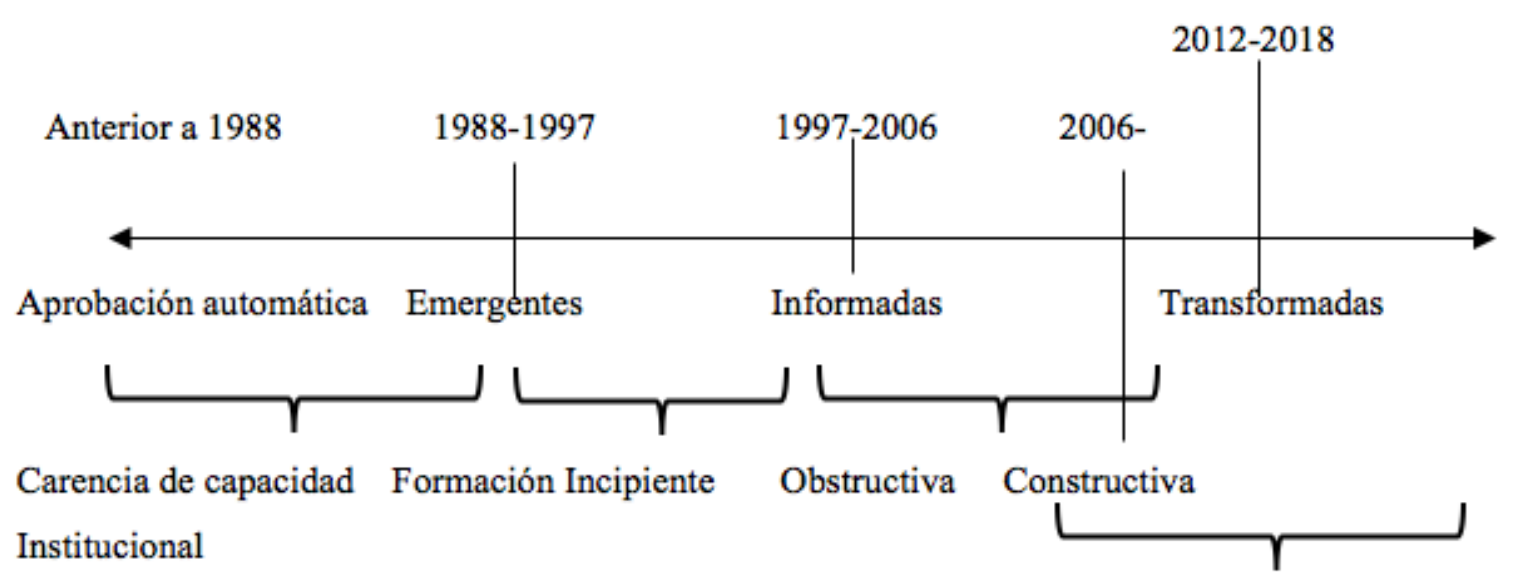

Proceso de Consolidación Inconcluso

Elaboración propia con base en Díaz (2000) y Saiegh (2010)

En la línea del tiempo de la figura dos, este proceso se percibe en cada etapa de transformación identificada en años en los que los actores y las instituciones se fueron conformando. Hasta antes de 1988, el poder legislativo en México se caracterizaba por el predominio del Ejecutivo sobre el Legislativo ocasionado por el apoyo mayoritario y hegemónico, así como la disciplina impuesta por el partido revolucionario institucional, lo que hacía del Congreso mexicano un parlamento de aprobación automática. La 
Artigo | Institucionalización del Congreso Federal Mexicano. Transición democrática y cambio organizacional (ESCAMILLA, Laura Valencia)

organización centralizada en la que se basaba el legislativo, había favorecido al PRI y al presidente, porque este último, al ser jefe de Estado, de gobierno y de su partido, le otorgaba la facultad metaconstitucional de repartir las candidaturas electorales y las dirigencias legislativas. En este caso, las mayorías afines al presidente se aseguraban, porque al interior del Congreso se estableció un sistema de gobierno basado en una comisión unipartidista conocida como la Gran Comisión, cuya autoridad emanaba directamente del presidente de la Gran Comisión, designado a su vez por el presidente de la República. ${ }^{7}$

A partir de 1988 hasta 1997, cuando el sistema de partidos deja de ser un sistema de partido hegemónico, para convertirse en uno con partido dominante y fuerzas opositoras más competitivas, se advierte un Congreso emergente donde una de las primeras tareas de los grupos parlamentarios de los partidos de oposición cuando incrementaron su dotación de asientos, fue despojar al PRI del monopolio de la organización legislativa y transferir dichos poderes a un órgano multipartidista conocido inicialmente como Comisión de Régimen Interno y Concertación Política, creado en la LV Legislatura (1991-1994), que a su vez incidió en la composición plural de las comisiones legislativas (parlamento racionalizado). En cuanto a los sistemas de información nacen incipientes recursos técnicos y tecnológicos como la tabla electrónica de votaciones, en donde por primera vez los ciudadanos tenían la posibilidad de conocer los registros de votación de sus representantes.

En 1999 se llevó a cabo la reforma integral del Congreso (parlamento estructurado) al plantear la reformulación de su propia ley orgánica en la que el órgano de dirección interno, ahora renombrada Junta de Coordinación Política (creada en 1999) tenía por objetivo, además de integrar a los coordinadores de los grupos parlamentarios representados por cada Cámara, impulsar la conformación de acuerdos parlamentarios relacionados con el contenido de las agendas de los partidos políticos a través de la Conferencia para la Dirección y Programación de los Trabajos Legislativos.

La transparencia y los sistemas de información fueron dos elementos adicionales considerados por las reformas propuestas en ese periodo. La difusión del trabajo

\footnotetext{
7 Los poderes de la Gran Comisión eran extensos, abarcaban desde la preparación de la lista de integrantes de cada comisión legislativa, el nombramiento de los principales cargos administrativos, la asignación de los recursos, hasta la selección de los miembros de la Mesa directiva.
} 
Artigo | Institucionalización del Congreso Federal Mexicano. Transición democrática y cambio organizacional (ESCAMILLA, Laura Valencia)

legislativo estuvo a cargo del Canal del Congreso, así como los servicios de información en línea bajo la dirección de la Secretaría Parlamentaria. ${ }^{8}$ Al mismo tiempo se reconoció la necesidad de contar con cuerpos de apoyo técnico en la elaboración de iniciativas y sistemas de información básico y especializado, así como actividades de investigación y sondeos para conocer las problemáticas y análisis de posibles soluciones (LOCGEUM).

En el mismo sentido los sistemas de control se reforzaron en tanto que se crearon una serie de instancias encargadas de fiscalizar, supervisar y controlar al Ejecutivo; por ejemplo, la Auditoría Superior de la Federación, -quien sustituye a la Contaduría Mayor de Hacienda-, fue creada en el año 2000 para la revisión de la cuenta pública, instancia que tiene la capacidad de auditar a los poderes públicos, además de sancionar y fincar responsabilidad en caso de daño al erario público (artículos 73, 74, 76 y 80 constitucionales).$^{9}$

Durante este periodo de construcción del propio congreso se gestaron las primeras experiencias de gobierno dividido que trajeron como consecuencia amplios periodos de obstrucción (propios del parlamentarismo "salvaje") a decisiones legislativas expedidas por el gobierno. Al mismo tiempo, se observó un proceso de

\footnotetext{
${ }^{8}$ De acuerdo a lo dispuesto por el artículo 49 de la Ley Orgánica del Congreso General de los Estados Unidos Mexicanos (LOCGEUM), la Secretaría de Servicios Parlamentarios tiene como función ofrecer los siguientes servicios:

a) Servicios de Asistencia Técnica a la Presidencia de la Mesa Directiva, que comprende los de: comunicaciones y correspondencia; turnos y control de documentos; certificación y autentificación documental; instrumentos de identificación y diligencias relacionados con el fuero de los legisladores; registro biográfico de los integrantes de las legislaturas; y protocolo, ceremonial y relaciones públicas;

b) Servicios de la Sesión, que comprende los de: preparación y desarrollo de los trabajos del Pleno; registro y seguimiento de las iniciativas o minutas de ley o de decreto; distribución en el Pleno de los documentos sujetos a su conocimiento; apoyo a los Secretarios para verificar el quórum de asistencia; cómputo y registro de las votaciones; información y estadística de las actividades del Pleno; elaboración, registro y publicación de las actas de las sesiones; y registro de leyes y resoluciones que adopte el Pleno; c) Servicios de las Comisiones, que comprende los de: organización y asistencia a cada una de ellas a través de su Secretario Técnico; registro de los integrantes de las mismas; seguimiento e información sobre el estado que guardan los asuntos turnados a Comisiones; y registro y elaboración del acta de sus reuniones;

d) Servicios del Diario de los Debates, que comprende los de: elaboración integral de la Versión Estenográfica; del Diario de los Debates; y de la Gaceta Parlamentaria;

e) Servicios del Archivo, que comprende los de: formación, clasificación y custodia de expedientes del Pleno y las Comisiones; y desahogo de las consultas y apoyo documental a los órganos de la Cámara y a los legisladores; $y$

f) Servicios de Bibliotecas, que comprende los de: acervo de libros; hemeroteca; videoteca; multimedia; museografía; e informática parlamentaria.

${ }^{9}$ Hasta 2009 la ley de fiscalización y rendición de cuentas de la federación es expedida como el principal instrumento normativo de rendición de cuentas respecto a la cuenta pública que tiene como objetivo regular la autonomía técnica y gestión de la Auditoría. En 2015 la ley es sometida a una reforma a fin de integrar el sistema nacional anticorrupción a la entidad fiscalizadora (MÁRQUEZ y TOVAR, 2018).
} 
Artigo | Institucionalización del Congreso Federal Mexicano. Transición democrática y cambio organizacional (ESCAMILLA, Laura Valencia)

transformación en tanto, el congreso es más propositivo en su labor legislativa (por ejemplo, en 2006 fue obligatoria la presentación de las agendas legislativas de cada grupo parlamentario representado en el congreso). En 2009 y 2010 se abren canales de acceso ciudadano a la creación de instancias de gestoría ciudadana; y se reglamenta el cabildeo, al mismo tiempo que los sistemas de transparencia e información experimentaron un proceso de consolidación desde la expedición en el año 2000 del Estatuto de la Organización Técnica y Administrativa y del Servicio de Carrera del Congreso. ${ }^{10}$

En cuanto a los servicios de asesoría técnica, desde 1997 existen en la Cámara de Diputados centros de investigación que apoyan a los legisladores en su quehacer de legislar: Centro de Estudios de Desarrollo Rural Sustentable y la Soberanía Alimentaria (CEDRSSA) creado en 2004, Centro de Estudios de Derecho e Investigaciones Parlamentarias (CEDIP), Centro de Estudios de las Finanzas Públicas (CEFP) ambos instalados en 1997, Centro de Estudios Sociales y de Opinión Pública (CESOP) instaurado en el año 2000, y en el año 2005 surge el Centro de Estudios para el Adelanto de las Mujeres y la Equidad de Género (CEAMEG). El objetivo de estos centros ha sido brindar apoyo técnico e información analítica a los diputados y a las comisiones legislativas. Dichos centros se constituyeron como instancias de carácter institucional y no partidista, integrado por especialistas en las diferentes ramas de conocimiento ofrecido por los órganos de consulta (CABRERA, 2017, p. 6).

El Senado de la República por su parte, cuenta con el Instituto de Investigaciones Legislativas del Senado de la República (IILSEN). Se trata de un órgano especializado dependiente de la Mesa Directiva encargado de desarrollar actividades de investigación, estudios y análisis relacionados con las Competencias del Senado, así como el establecimiento de vínculos institucionales con organismos públicos y privados, nacionales y extranjeros con el objeto de apoyar el trabajo legislativo del Senado (CESOP, 2004).

A pesar de que los centros representan un apoyo sustancial y contribuyen a la profesionalización de los legisladores, por el número de investigadores; los centros

\footnotetext{
${ }^{10}$ Hay que mencionar que a los sistemas de información internos se suman otros interesados en generar y ordenar la información legislativa como el Sistema de Información Legislativa (SIL) y el Sistema del Orden Jurídico Nacional, ambos proyectos generados por la Secretaría de Gobernación y que opera desde el 2003, así como el banco de información jurídica de la Suprema Corte de Justicia de la Nación.
} 
Artigo | Institucionalización del Congreso Federal Mexicano. Transición democrática y cambio organizacional (ESCAMILLA, Laura Valencia)

están limitados en cuanto a sus facultades. ${ }^{11}$ Estos se han limitado a proporcionar apoyo técnico e información analítica sin la capacidad de participar en las discusiones en comisiones. Es a petición de los representantes o de los grupos parlamentarios como se solicita la colaboración por lo que la actuación de dichos centros restringe su actuación a solicitud de los grupos. A pesar de que los integrantes de estos órganos basan su selección mediante un sistema de méritos, este no funciona sobre una base abierta a la población, sino mediante la recomendación de los legisladores. Lo que supone la sujeción institucional de los centros a los grupos parlamentarios.

Como se puede observar, el conjunto de transformaciones y facultades adquiridas por los órganos de representación nacional, dan sentido a las funciones legislativas otorgadas a la asamblea representativa en México mediante sus facultades reglamentaria, de veto, fiscalización y ejercicio del control sobre el presupuesto, la ley de ingresos, el endeudamiento, promover juicios políticos, crear comisiones de investigación, demandar la comparecencia de funcionarios públicos, analizar la celebración de convenios internacionales y nombrar a algunos miembros de la administración pública, ${ }^{12}$ entre las principales (artículos 73 al 80 constitucionales).

Sin embargo, a la luz de la evaluación de estos cambios se ha podido constatar que la transformación institucional del Congreso mexicano no ha sido suficiente. De acuerdo con el monitoreo de la Red Latinoamericana por la Transparencia Legislativa (RLTL), de la cual México es miembro desde 2012, el desarrollo estructural del congreso mexicano es limitado e insuficiente en unas áreas y constante en otras (RLTL, 2014). ${ }^{13}$

\footnotetext{
${ }^{11}$ Se debe destacar también que el personal dedicado a las áreas de investigación es más bien escaso y no permanente (el promedio de antigüedad es de dos a cuatro años), por ejemplo, la Secretaría de Servicios Parlamentarios (encargada de los centros) cuenta con 418 empleados, de los cuáles nueve son investigadores especializados, en tanto las áreas administrativas y operativas en conjunto suman más de tres mil seiscientos empleados (INTEGRALIA, 2012).

12 Pese a que la Constitución le otorga al Ejecutivo amplias facultades para nombrar a los miembros de la administración pública, esta prerrogativa es compartida en algunos casos por el Congreso. Tales nombramientos se refieren al cuerpo diplomático, algunos en la Armada, niveles superiores de la Secretaría de Hacienda, la Suprema Corte de Justicia, el gobernador del Banco de México, el Procurador General de la República y algunos más destacados en los Artículos 76 y 80 Constitucionales.

${ }^{13} \mathrm{En} 2012$ la comunidad parlamentaria internacional adoptó la Declaración sobre Transparencia Parlamentaria debatida en Washington D.C, evento organizado por el National Democratic Institute Sunlight Foundation y la Red Latinoamericana por la Transparencia Legislativa, posteriormente firmada en Roma en septiembre de 2012. De entre los acuerdos suscritos por los países firmantes destacan: transparentar la información parlamentaria, facilitar el acceso a la información a los ciudadanos, permitir el acceso electrónico y el análisis de la información parlamentaria en línea y formatos abiertos, entre los principales puntos. El objetivo del compromiso es el monitoreo de los cuerpos legislativos para aumentar
} 
Artigo | Institucionalización del Congreso Federal Mexicano. Transición democrática y cambio organizacional (ESCAMILLA, Laura Valencia)

En 2014 la asamblea mexicana obtuvo un puntaje de 44.6 sobre 100, mientras que para 2016 la calificación incrementa ligeramente en 58.3 puntos, la evaluación de 2018 prácticamente se mantiene respecto a la anterior, pues apenas avanza unas décimas quedando en 58.09, lo que significa que de acuerdo con las cuatro dimensiones que valora el índice de la Red: normativa; labor del Congreso; presupuesto y gestión administrativa; y atención y participación ciudadana, solo la primera y la última, registraron avances en términos de eficacia, transparencia y responsabilidad frente a sus representados. En tanto las áreas que corresponden a la transparencia presupuestal y gestión administrativa, así como la eficacia de la labor legislativa, fueron dos actividades que recibieron menor calificación en los años monitoreados por el índice como se muestra en la gráfica dos.

su eficacia, abrirlos a la transparencia y hacerlos responsables frente a sus representados (OPENING PARLIAMENT.ORG, 2012).

Como parte de los compromisos adoptados, la región latinoamericana emprende acciones a través de diversas iniciativas promovidas algunas por la Red Parlamentaria Interamericana Pro Transparencia, Acceso a la Información Pública y Probidad, constituida en 2012 en Santiago de Chile, así como la Alianza por el Parlamento Abierto firmado en México en septiembre de 2014. Ambos acuerdos comprometen la participación de algunos países de la región como Chile, Argentina, México, Colombia, Ecuador, Guatemala, Perú, Venezuela, Uruguay, Paraguay, El Salvador y Costa Rica.

La intención del monitoreo ha consistido por un lado en el fortalecimiento institucional de los congresos en América Latina cuyo objetivo es: apoyar la gestión legislativa, incorporar nuevas tecnologías e instrumentar mejores sistemas de información. Por otro lado, las medidas buscan combatir la corrupción, adoptando normas de transparencia y derecho a la información, así como órganos que garanticen la rendición de cuentas y la interlocución ciudadana. Ambos objetivos han sido discutidos e implementados de tal manera que las reuniones de las asociaciones en pro de la transparencia han sido anuales de 2012 a 2016 con el fin de homologar las metodologías de monitoreo aplicados a los países de la región firmantes (OPENING PARLIAMENT.ORG, 2012). 
Artigo | Institucionalización del Congreso Federal Mexicano. Transición democrática y cambio organizacional (ESCAMILLA, Laura Valencia)

Gráfica 2 Evaluación Legislativa del Congreso Mexicano

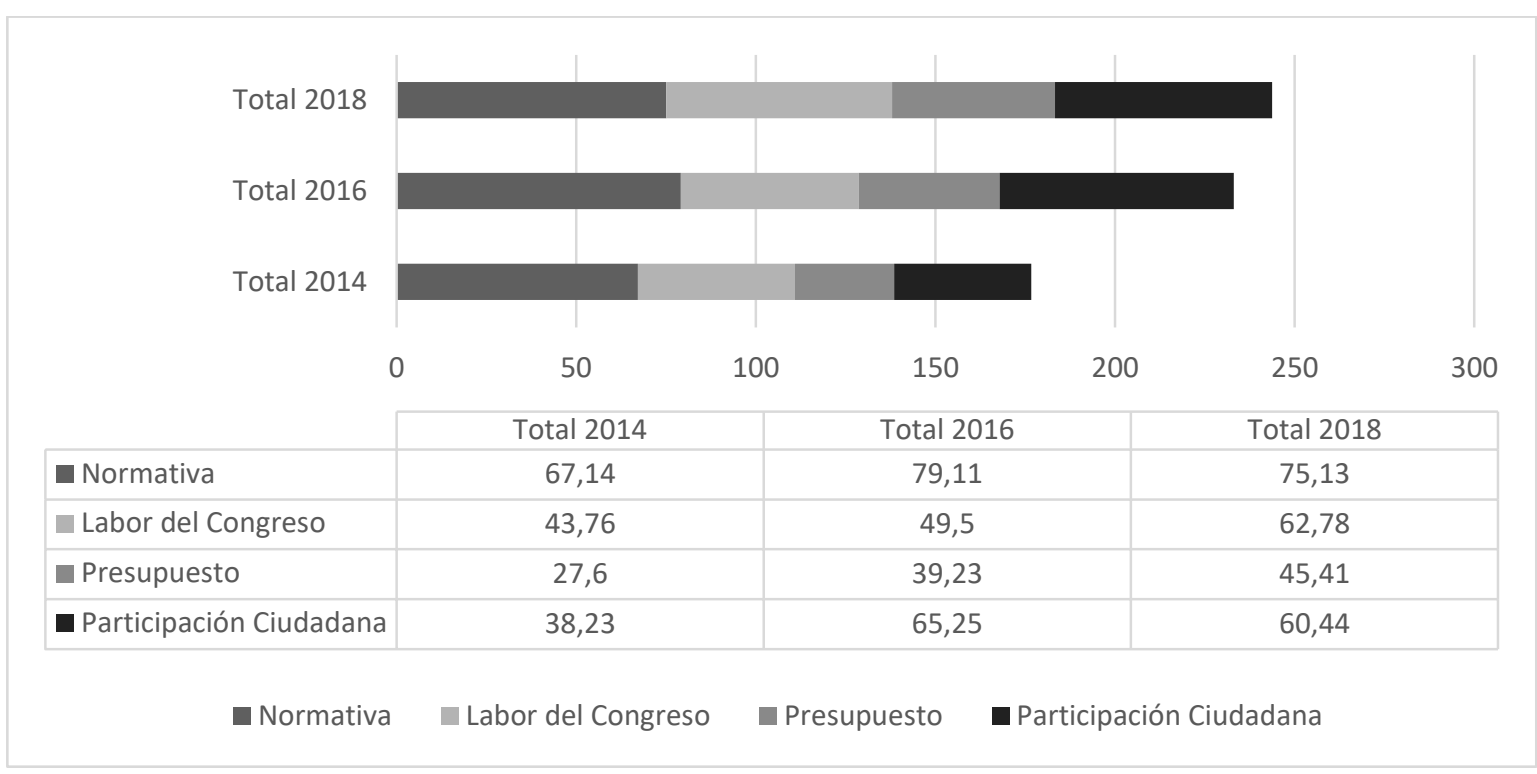
(2018)

Fuente: Elaboración propia con base en datos de la Red Latinoamericana por la Transparencia

La dimensión normativa y participación ciudadana fueron dos de las medidas que registraron avances entre las dos primeras evaluaciones y presentan ligeros retrocesos en 2018, los indicadores más destacados son la existencia de diversas reglamentaciones en materia de cabildeo, publicidad de las sesiones del pleno, actividades de las comisiones y la existencia de una oficina de atención y vinculación ciudadana, así como la introducción de acceso ciudadano mediante mecanismos de parlamento abierto. Contrariamente, se registró la ausencia de la obligatoriedad de presentar informes de gestión de parte de los legisladores, así como la ausencia de oficinas subnacionales de vinculación ciudadana.

En la variable labor del congreso fue posible identificar la ausencia en el cumplimiento de documentos que registren la memoria legislativa de las comisiones en las que se sondeen la asistencia de las comisiones, las votaciones de las sesiones e información sobre asesorías externas, así como la inexistencia de registro de obsequios que reciben los legisladores.

En el ámbito presupuestal, la evaluación arroja la calificación más baja debido a la ausencia en la visibilidad de convocatorias a concurso para la integración de plazas en el Congreso, inexistencia de transparencia de información sobre asesores y staff parlamentario, así como el apoyo del personal en los distintos órganos de la estructura legislativa (RLTL, 2018, p. 36-39). 
Artigo | Institucionalización del Congreso Federal Mexicano. Transición democrática y cambio organizacional (ESCAMILLA, Laura Valencia)

En ese tenor, México, es uno de los tres congresos con mayor presupuesto en el mundo (UNIÓN INTERPARLAMENTARIA, 2012), al mismo tiempo, el Poder Legislativo mexicano reporta índices de transparencia muy limitados en el manejo de los recursos. En el cuadro tres se puede apreciar que la referencia de México con otros países latinoamericanos nos da una idea de la opacidad en el manejo de recursos de los legisladores, dado que la ley no obliga a los representantes a rendir cuentas sobre sus gastos, ni a brindar informes financieros o a realizar auditorías externas que notifiquen sobre salarios, prestaciones, estructuras administrativas, asesorías contratadas por los congresistas o contrataciones públicas de servicios. Como se puede constatar en el cuadro los países con mayores asignaciones presupuestales, al mismo tiempo registran bajos niveles de transparencia en este rubro.

Cuadro 3. Asignaciones presupuestales e índice de transparencia

\begin{tabular}{|c|c|c|c|c|}
\hline País & $\begin{array}{l}\text { Asignación } \\
\text { presupuestal (en } \\
\text { millones de } \\
\text { dólares) }\end{array}$ & $\begin{array}{l}\text { Índice } \\
\text { de transparencia } \\
\text { presupuestal* } \\
\text { (2014) }\end{array}$ & $\begin{array}{l}\text { Índice } \\
\text { de transparencia } \\
\text { presupuestal* } \\
(2016)\end{array}$ & $\begin{array}{l}\text { Índice } \\
\text { de transparencia } \\
\text { presupuestal* } \\
\text { (2018) }\end{array}$ \\
\hline México & $8,878.1$ & 0.28 & 0.39 & 0.45 \\
\hline Argentina & $5,016.5$ & 0.20 & 0.27 & 0.37 \\
\hline Colombia & $2,468.8$ & 0.48 & 0.55 & 0.60 \\
\hline Venezuela & 2,276 & 0.6 & 0.7 & 0 \\
\hline Chile & $1,633.2$ & 0.61 & 0.61 & 0.54 \\
\hline Costa Rica & 498.1 & 0.79 & 0.79 & 0.77 \\
\hline
\end{tabular}

*El índice tiene un rango entre 0 y 1 , los cercanos al cero son los menos transparentes y los cercanos al uno son los más transparentes

S/D: sin datos

Fuente: Elaboración propia con base en datos de la Unión Interparlamentaria, 2012; Red Latinoamericana por la Transparencia Legislativa, (2018).

Finalmente, la dimensión atención y participación ciudadana tuvo avances significativos, particularmente la existencia de mecanismos de acceso a la información pública como el canal de televisión del Congreso, la página web e información pública sobre los legisladores. Pese a las mejoras, las faltantes se localizaron en la carencia de mecanismos que involucren la participación ciudadana en la labor legislativa.

La desventaja del Congreso mexicano se observa claramente en el ámbito de transparencia presupuestal y labor del Congreso. Es decir, el proceso de modernización 
Artigo | Institucionalización del Congreso Federal Mexicano. Transición democrática y cambio organizacional (ESCAMILLA, Laura Valencia)

y cambio institucional en el poder legislativo mexicano continúa inconcluso dado que a pesar de la adecuación normativa y la implementación de tecnologías, sistemas de información especializado, y la construcción de redes informáticas, son evidentes las asimetrías de información y conocimiento del Legislativo respecto del Ejecutivo al momento de legislar, de mejorar la rendición de cuentas horizontal, de su capacidad de control y fiscalización gubernamental; además la construcción de redes informáticas que den acceso al control y a la participación ciudadana cuyo fin es ampliar la inclusión de los representados en las decisiones legislativas, dichos mecanismos se muestran limitados, ambiguos y carentes de vinculación con la opinión de los ciudadanos, sin contar la baja capacidad de propio congreso para la instauración y consolidación democráticas vía reformas constitucionales.

\section{Profesionalización Legislativa}

A este proceso de transformación del Poder Legislativo mexicano se debe incluir el perfil de los legisladores en cuanto a la carrera político-legislativa; la relación con los órganos de decisión legislativa y la preparación académica del diputado, como variables a considerar para el análisis de las decisiones del grupo parlamentario y la agenda legislativa.

En este tenor, la preparación del representante contribuye a la institucionalización además de la profesionalización del trabajo legislativo. Se debe mencionar que hasta ahora no hay un acuerdo entre los estudiosos sobre el tópico.

No obstante, las limitantes que ofrece la actividad legislativa para la profesionalización, es posible afirmar que, la destreza de los legisladores se enfoca en: dar respuesta a las demandas de sus representados mediante la formulación y elaboración de iniciativas de ley que conjugan intereses de los legisladores y sus partidos con la respuesta a las demandas de sus representados. Además, se relaciona con la supervisión y control gubernamental, así como el control ciudadano y la rendición de cuentas de los funcionarios. ${ }^{14}$

\footnotetext{
${ }^{14}$ En la actualidad la complejidad del manejo de los asuntos públicos, han provocado cambios en los roles tradicionales de las instituciones legislativas. Básicamente los parlamentos asumen tareas tales como la representación y agregación de intereses; elaboración de leyes; supervisión y vigilancia. Sin embargo, se debe tomar en cuenta que la complejidad de los sistemas políticos dificulta la división de poderes en
} 
Artigo | Institucionalización del Congreso Federal Mexicano. Transición democrática y cambio organizacional (ESCAMILLA, Laura Valencia)

La profesionalización del legislador depende de varios elementos: la experiencia legislativa, la carrera política, la capacitación partidista y los sistemas de información legislativos. Las dos primeras resultan de los esfuerzos individuales del legislador, mientras que las dos últimas se refieren al apoyo interno que los legisladores reciben de sus organizaciones partidistas, así como de la organización legislativa (anteriormente analizadas).

La experiencia legislativa se entiende como el tiempo (años, legislaturas, periodos) que un legislador permanece en el congreso. Ocupar una curul implica aprender o dominar el proceso y la técnica legislativa, ya que la práctica profundiza el conocimiento adquirido y favorece la actividad parlamentaria. (CAMPOS, 2003).

Con el tiempo, el conocimiento y la experiencia que los representantes acumulan en un desempeño continuo de sus tareas, redunda en la supervisión y control parlamentario más eficaz sobre el gobierno; además de la madurez y especialización adquiridas por este medio, la capacitación eleva la calidad y el rendimiento de sus intervenciones, condición cuanto más necesaria frente a una burocracia administrativa mejor dotada de apoyo logístico (BÉJAR, 2001, p. 52).

En la medida que los representantes adquieren mayor experiencia, su capacidad para legislar mejora, ya que el tiempo consolida su aprendizaje (RUBIO, 2005). Una opción viable para la acumulación de experiencia ha sido la reelección inmediata de los legisladores. La reelección consecutiva durante uno o varios periodos produce parlamentarios informados y educados en las diversas materias y asuntos legislativos. (DE ANDREA, 2002).

En México, la no reelección inmediata ha sido causa de un debate histórico que involucra el carácter del régimen y el control de las carreras de las elites políticas en manos del partido hegemónico y su líder en turno desde 1933. En la actualidad, esa postura dejó de tener vigencia ${ }^{15}$ y no será sino hasta la reforma política de 2014 que se

cuanto a tareas específicas y hoy día, los cuerpos representativos, además de reforzar sus funciones tradicionales, han ampliado sus roles al grado que hay quienes consideran algunas otras como influencia o diseño de las políticas públicas, socialización y educación política; racionalización del mercado; reclutamiento y entrenamiento de personal así como diplomacia parlamentaria (VALENCIA, 2016).

15 Desde 1964 surgen las primeras propuestas de restauración de la reelección inmediata, durante el proceso de democratización las propuestas en torno a esta se acumularon de tal manera que hasta el 2010, se pueden contabilizar 35 propuesta a favor de la reelección inmediata, provenientes de los miembros de la cámara de diputados; nueve de los integrantes de la cámara alta de 2002 a 2009 y una de 
Artigo | Institucionalización del Congreso Federal Mexicano. Transición democrática y cambio organizacional (ESCAMILLA, Laura Valencia)

incluye la modificación al artículo 59 constitucional en el que se restablece la reelección consecutiva de los legisladores, cuya vigencia daría inicio con los representantes electos en 2018. La norma estipula periodos de permanencia consecutiva por doce años para los diputados (cuatro periodos de tres años cada uno) e igual número para los senadores (dos periodos de seis años cada uno).

No obstante que la regla no aplicó para los legisladores del periodo de estudio, se debe mencionar que, a pesar de la interrupción del mandato, los legisladores mexicanos han tenido la posibilidad de acumular experiencia legislativa en la medida en la que continúan una carrera legislativa al transitar de un congreso a otro.

Respecto a la experiencia acumulada son pocos los países latinoamericanos que mantienen niveles constantes de permanencia en el cargo. Como puede observarse en la gráfica dos, de acuerdo con el Observatorio del Poder Legislativo en América Latina; Chile, Argentina y Brasil, en un periodo de 1995 a 2008, mantuvieron un promedio por encima del $50 \%$ de legisladores que han sido reelectos en la cámara baja; mientras países como México, Costa Rica (con reelección no consecutiva); Bolivia, Ecuador y Guatemala registran promedios que oscilan entre el 3 y $13 \%$ de integrantes reelectos o reincidentes (para aquellos países sin reelección consecutiva) en el mismo cargo. La reelección en el senado para aquellos sistemas bicamerales es mayor a la de la cámara baja en el caso de Argentina, Brasil y República Dominicana. En el caso de México es interesante que la reincidencia de los pocos legisladores que repiten en el cargo solo se registra en la Cámara de Diputados y no así en la de Senadores, posiblemente el fenómeno se debe a que los periodos en la cámara alta son el doble (seis años) que en la Cámara de Diputados (tres años).

parte del entonces presidente Felipe Calderón. Ninguna de ellas contó con el consenso suficiente para ser discutida y aprobada por los Congresos (VALENCIA, 2018, p. 88). 
Gráfica 2. Reelección Legislativa en América Latina (1995-2008)

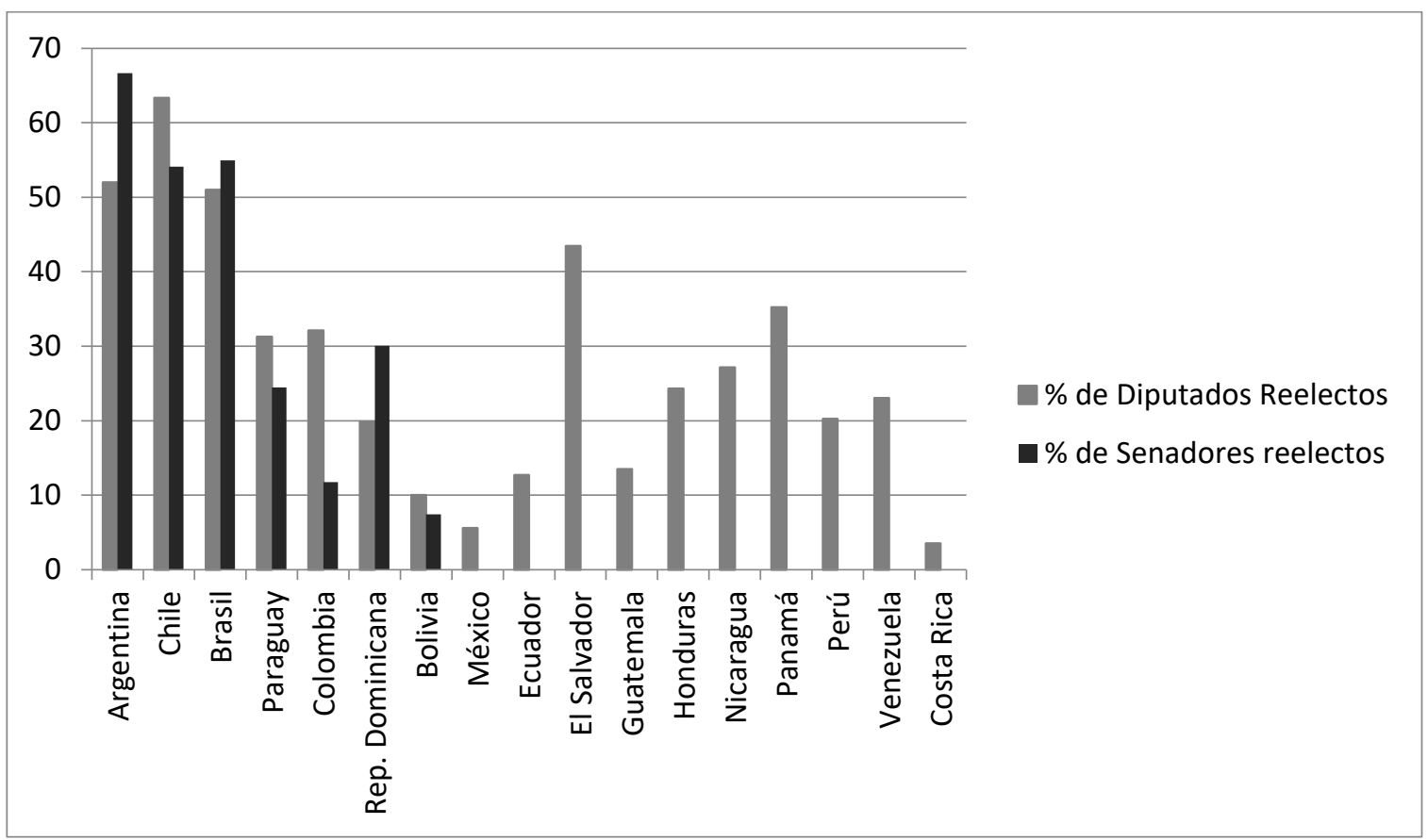

CD: Cámara de Diputados Cambio de leyenda del gráfico

CS: Cámara de Senadores

Fuente: Elaboración propia con base en Legislatina (2020).

En este sentido, Emma Campos (2003) confirma de igual manera que la tendencia de los legisladores mexicanos a continuar con una carrera legislativa es baja. Durante poco más de sesenta años (de 1934 a 1994 periodo en el que la autora elabora el estudio) Campos ha constatado que el Congreso mexicano ha estado integrado por amateurs. Pese a que el partido predominante (PRI) mantenía el aseguramiento de las ganancias electorales de sus candidatos, la reincidencia de los legisladores en promedio, apenas sobrepasaban $14 \%$ de experiencia previa como legislador (local y federal). Además, se debe tomar en cuenta que la reincidencia no sobrepasaba más allá de un periodo. Es decir, las ambiciones de los congresistas mexicanos han sido progresivas dado que el congreso resulta un trampolín hacia otros cargos públicos más rentables y de prestigio para acumular experiencia política más que legislativa.

Desde la formación de gobiernos divididos en 1997, el escenario del parlamento mexicano ha sido de legislaturas fragmentadas y gobiernos de minoría o mayorías en coalición, situación que representa el declive del control presidencial en la asignación de cargos públicos, por tanto, los ascensos progresivos ya no dependen de la promoción del jefe del ejecutivo, sino de los esfuerzos individuales de los legisladores por conservar 
Artigo | Institucionalización del Congreso Federal Mexicano. Transición democrática y cambio organizacional (ESCAMILLA, Laura Valencia)

el cargo y/o buscar la promoción de sus carreras en ámbitos distintos a los tradicionales (por ejemplo vía el "transfuguismo") por lo que se esperaría carreras legislativas más autónomas, afianzadas e independientes; de ahí que la expectativa sobre la reforma del 2014 aplicada a los legisladores que ingresan en 2018, sea de independencia, respecto a la postulación presidencial pero no con respecto a las dirigencias de sus partidos, en tanto que, una de las limitantes de la Ley a la reelección, es la postulación de candidatos por el mismo partido, situación que reduce el transfuguismo y refuerza el papel de las dirigencias políticas para la postulación de aspirantes a los cargos de reelección legislativa (art. 59 constitucional).

Históricamente, como se observa en el récord registrado por la gráfica dos el porcentaje de experiencia legislativa federal acumulada, fundamentalmente de los diputados, no dista de los datos registrados por Emma Campos en su momento. En 1997 el $14.4 \%$ de los integrantes de la cámara baja reportó tener alguna experiencia como legislador federal. En el año 2000 el porcentaje de legisladores con experiencia aumentó ligeramente un punto porcentual (15.8); para el 2003 la tendencia es a la baja (12.4), el aumento es considerable en la siguiente legislatura (22) y se reduce en la LXI legislatura (2009-2012) a 17\%, como se observa en la gráfica tres, es decir, ni los gobiernos unificados, ni los divididos han tenido efecto en la reincidencia de los legisladores a ocupar cargos legislativos, la reelección no inmediata se ha mantenido estable con respecto a los gobiernos unificados priístas, lo que supone que el diseño de la no reelección y el férreo control de los partidos en la selección de candidatos son un fuerte inhibidor de la carrera legislativa. En promedio, la diferencia entre los representantes reincidentes o con experiencia acumulada es del 65\%, 2006 es el año que registra el menor número de legisladores amateurs (56\%), en contraste, 2003 es el año legislativo con el porcentaje más alto de asambleístas carentes de experiencia legislativa (76\%). 


\section{Gráfica 3. Diputados con y sin experiencia legislativa en México (1979-2009)}

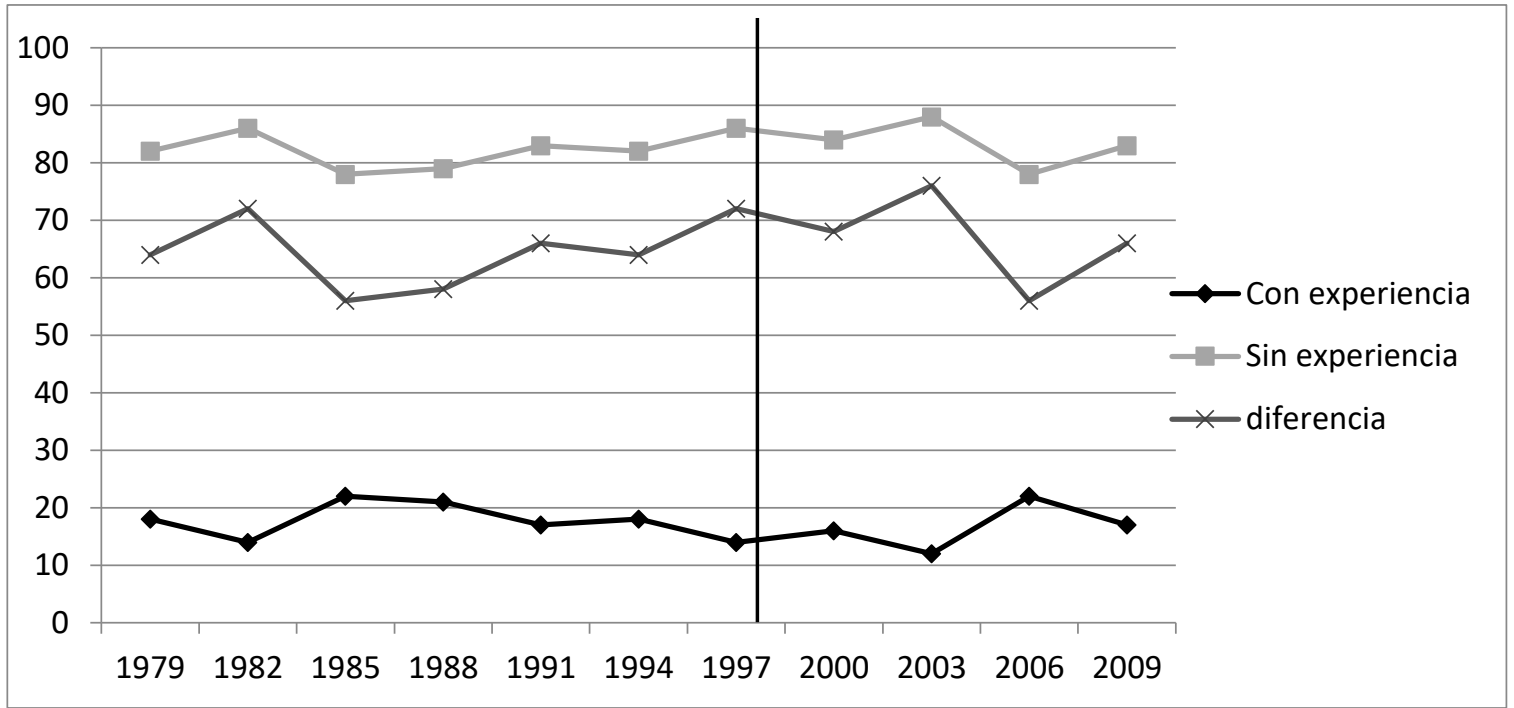

La línea vertical marca el periodo de gobiernos no mayoritarios

Fuente: Elaboración propia con base en Campos, Emma (2003), Sánchez y Trejo (2012)

Respecto a la magnitud de la variabilidad de la experiencia de los representantes se debe destacar que no hay una constante ascendente o descendente de experiencia, conforme al índice de experiencia legislativa que se muestra en el cuadro 4, esta aumentó en 22 por ciento, como su máximo, en diferentes periodos, en 1985 y 2006, luego en 1988 el incremento se dio en 175 respecto a la experiencia registrada en 1979, sin embargo, el índice registra el reducido interés de los legisladores por continuar una carrera legislativa. Sus ambiciones los llevan a seguir una línea ascendente en el momento de escalar en los cargos de elección popular. 
Artigo | Institucionalización del Congreso Federal Mexicano. Transición democrática y cambio organizacional (ESCAMILLA, Laura Valencia)

Cuadro 4. Índice de experiencia legislativa Federal

\begin{tabular}{|l|l|l|}
\hline Año & Con experiencia & Sin experiencia \\
\hline 1979 & 1 & 1 \\
\hline 1982 & 0.78 & 1.05 \\
\hline 1985 & 1.22 & 0.95 \\
\hline 1988 & 1.17 & 0.96 \\
\hline 1991 & 0.94 & 1.01 \\
\hline 1994 & 1.00 & 1.00 \\
\hline 1997 & 0.78 & 1.05 \\
\hline 2000 & 0.89 & 1.02 \\
\hline 2003 & 0.67 & 1.07 \\
\hline 2006 & 1.22 & 0.95 \\
\hline $\mid 2009$ & 0.94 & 1.01 \\
\hline
\end{tabular}

Elaboración propia con base en Campos, Emma (2003), Secretaría de Gobernación (2020)

A pesar de que los números muestran una tendencia establecida respecto a la carrera legislativa de los diputados federales, es interesante hacer notar que el estudio de campo elaborado para este documento, también registró la experiencia adquirida como legisladores locales, los resultados al respecto fueron reveladores; para empezar el porcentaje es considerablemente mayor respecto a la experiencia federal, y en segundo lugar, la tendencia de quienes poseen este tipo de experiencia es claramente ascendente. En el cuadro 5 donde se muestra el índice de experiencia local se observa que poco más del $35 \%$ de los legisladores federales en México cuanta con alguna experiencia previa como representantes en los congresos locales, esta tendencia se ha incrementado porque como lo muestra el cuadro, el Congreso ha aumentado su volumen de legisladores con esta característica. A diferencia de la experiencia federal, la local si mantiene una tendencia ascendente, de tal manera que la experiencia acumulada aumentó en $25 \%$ respecto a la LVII legislatura. Lo que significa que la experiencia como representante más que como legislador es más importante para la postulación de los partidos, que la experiencia legislativa federal. Esto confirma la aseveración anterior, los legisladores mexicanos mantienen sus vínculos locales en función de una carrera ascendente por otros cargos de elección popular antes que una carrera legislativa local o federal. 


\section{Cuadro 5. Índice de Experiencia legislativa local previa a la asignación del cargo}

\begin{tabular}{|c|c|c|c|c|c|c|c|c|c|c|}
\hline \multirow{3}{*}{ Experiencia } & \multirow{2}{*}{\multicolumn{2}{|c|}{$\begin{array}{l}\text { Legislatura } \\
\text { LVII } \\
(1997- \\
2000)\end{array}$}} & \multirow{2}{*}{\multicolumn{2}{|c|}{$\begin{array}{l}\text { Legislatura } \\
\text { LVIII } \quad(2000- \\
2003)\end{array}$}} & \multirow{2}{*}{\multicolumn{2}{|c|}{ 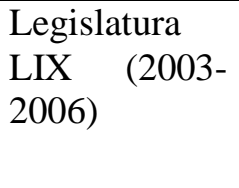 }} & \multirow{2}{*}{\multicolumn{2}{|c|}{$\begin{array}{l}\text { Legislatura } \\
\text { LX (2006- } \\
2009\end{array}$}} & \multirow{2}{*}{\multicolumn{2}{|c|}{$\begin{array}{l}\text { Legislatura } \\
\text { LXI (2009- } \\
\text { 2012) }\end{array}$}} \\
\hline & & & & & & & & & & \\
\hline & \# & IEL & \# & IEL & \# & IEL & \# & IEL & \# & IEL \\
\hline $\begin{array}{l}\text { Sin } \\
\text { experiencia }\end{array}$ & 334 & 100 & 351 & 105.08 & 304 & 91.01 & 322 & 96.40 & 304 & 91.01 \\
\hline $\begin{array}{l}\text { Con } \\
\text { experiencia }\end{array}$ & 155 & 100 & 149 & 96.12 & 195 & 125.80 & 175 & 112.90 & 193 & 124.51 \\
\hline
\end{tabular}

Elaboración propia con base en Sánchez y Trejo (2012) y Cámara de Diputados en Línea (2020)

Una posible explicación respecto al fenómeno es que desde la formación del gobierno dividido en México (1997), los partidos, reformaron sus normas de postulación al privilegiar el liderazgo local (PAN), el liderazgo y control de los grupos de interés (PRI) y el arrastre social de los representantes (PRD).

Esta situación novedosa ha producido transformaciones en el interés de los partidos por postular e integrar cámaras de legisladores experimentados, este es el caso de la Cámara de Senadores, -quienes en comparación con los diputados- son los que más experiencia acumulada poseen:

\begin{tabular}{|c|c|c|c|c|c|c|}
\hline \multicolumn{7}{|c|}{ Cuadro 6 Experiencia legislativa Federal por periodos } \\
\hline \multirow{2}{*}{$\begin{array}{l}\text { Periodos* } \\
\text { Legislaturas }\end{array}$} & \multicolumn{4}{|c|}{ Cámara de Diputados } & \multirow{2}{*}{\multicolumn{2}{|c|}{$\begin{array}{l}\text { Cámara de } \\
\text { Senadores } \\
\text { LVIII-LIX** } \\
(2000-2006)\end{array}$}} \\
\hline & 2003) & (2000- & 2006) & (2003- & & \\
\hline 1 periodo & 66 & 13.2 & 25 & 15 & 41 & 30.1 \\
\hline 2 periodos & 30 & 6 & 10 & 2 & 21 & 15.4 \\
\hline 3 periodos & 8 & 1.6 & $\epsilon$ & 1.2 & 8 & 5.9 \\
\hline 4 periodos & 3 & .6 & 2 & .4 & 4 & 2.9 \\
\hline
\end{tabular}
anterioridad.

** A partir del año 2000, la Cámara de Senadores se renueva cada seis años, sin embargo, divide el trabajo legislativo en trienios similares como la Cámara de Diputados, por lo que los integrantes de la LVIII y LIX legislatura, son los mismos en la Cámara de Senadores. No obstante, se debe advertir que 19 senadores fueron sustituidos por sus suplentes en este periodo cuando decidieron postularse por otros cargos de elección popular u ocuparon puestos en la administración pública.

Elaboración propia con base en Sánchez y Trejo (2012) y Cámara de Diputados en Línea (2020) 
Artigo | Institucionalización del Congreso Federal Mexicano. Transición democrática y cambio organizacional (ESCAMILLA, Laura Valencia)

En el cuadro 6 se puede constatar que la magnitud de los diputados que reportan niveles de experiencia son menores a la registrada por los senadores ya que la mayoría de los diputados federales reincidentes lo ha sido solo por una vez, en contraste, el porcentaje de senadores dobla a los legisladores de la cámara baja en relación a la experiencia acumulada, lo que indica que el cargo de senador es un puesto cercano a la jerarquía organizacional partidista y cuya carrera legislativa, no necesariamente proviene del ascenso local. Por ejemplo, el número de legisladores con experiencia previa en asambleas locales y/o en cabeceras municipales es mayor entre los diputados, lo que indica que las fuentes de postulación de los partidos respecto a la cámara baja son los liderazgos locales vinculados a los puestos de representación y lucha social. Por su parte, los senadores reflejan una carrera más estática, vinculada a la dirección partidista como se muestra en el cuadro 6.

Identificar el grado de experiencia acumulado entre los legisladores es interesante, sobre todo cuando se relaciona con el número de representantes que ocupan algún cargo de dirección en la organización interna de la cámara, como integrantes de la mesa directiva, de las presidencias de las diversas comisiones y comités en los que se organiza el trabajo legislativo.

En conjunto se puede decir que el perfil de los legisladores con cargos en el Congreso verifica el peso que éstos tienen en la toma de decisiones y por tanto, se ostentan como representantes de la dirigencia nacional. En términos generales, los que ocuparon estos cargos fueron postulados como candidatos plurinominales, esto es, eran candidatos de la dirigencia nacional, fundamentalmente porque el $90 \%$ de éstos dominaron los diez primeros lugares de las listas, al mismo tiempo pertenecían a la elite nacional. Por ejemplo, se observó que todos los líderes parlamentarios ocupaban un cargo de dirección en los comités ejecutivos nacionales de sus partidos. 
Artigo | Institucionalización del Congreso Federal Mexicano. Transición democrática y cambio organizacional (ESCAMILLA, Laura Valencia)

\begin{tabular}{|c|c|c|c|c|c|c|c|c|}
\hline \multicolumn{9}{|c|}{ Cuadro 7 Relación de legisladores con experiencia legislativa y cargos de dirección en el Congreso } \\
\hline $\begin{array}{l}\text { Total de Diputados } \\
\text { LVIII (2000-2003) }\end{array}$ & \multicolumn{2}{|c|}{$\begin{array}{l}\text { Experiencia con } \\
\text { cargos }\end{array}$} & $\begin{array}{l}\text { Total Diputados } \\
\text { LIX (2003-2006) }\end{array}$ & \multicolumn{2}{|c|}{$\begin{array}{l}\text { Experiencia } \\
\text { con cargos }\end{array}$} & \multirow{2}{*}{$\begin{array}{l}\text { Total } \\
\text { Senadores 2000- } \\
2006 \\
\text { Con experiencia }\end{array}$} & \multicolumn{2}{|c|}{$\begin{array}{l}\text { Experiencia } \\
\text { con cargos }\end{array}$} \\
\hline Con experiencia & \multirow[b]{2}{*}{37} & \multirow[b]{2}{*}{34.57} & Con experiencia & \multirow[b]{2}{*}{27} & \multirow[b]{2}{*}{29.03} & & \multirow[b]{2}{*}{30} & \multirow[b]{2}{*}{40.5} \\
\hline 107 & & & 93 & & & 74 & & \\
\hline Sin experiencia & \multirow[b]{2}{*}{67} & \multirow[b]{2}{*}{17.04} & Sin experiencia & \multirow[b]{2}{*}{81} & \multirow[b]{2}{*}{19.9} & Sin experiencia & \multirow[b]{2}{*}{22} & \multirow[b]{2}{*}{42.3} \\
\hline 393 & & & 407 & & & 52 & & \\
\hline
\end{tabular}

Elaboración propia con base en Sánchez y Trejo (2012) y Cámara de Diputados en Línea (2020)

De acuerdo con el cuadro cinco, la afirmación de: a mayor experiencia, es más probable la asignación de puestos de dirección, esta no se cumple, ya que del total de diputados que reporta periodos de experiencia previa durante el periodo 2000-2006 solo $34 \%$ y $30 \%$ de los mismos ocupan cargos de dirección en la cámara baja, mientras que en la cámara alta, se aprovecha mejor la experiencia de los representantes territoriales, los datos arrojaron que el $40 \%$ de los senadores con experiencia previa obtuvo algún cargo de dirección al interior de la organización. Por años de experiencia acumulada, la mayor asignación la reciben los senadores que reportaron más de dos periodos acumulados.

La falta de experiencia legislativa de parte de los representantes federales es un tema que debería preocupar a los partidos políticos, sobre todo porque son ellos los más interesados en observar la carrera política de sus postulantes y preferir a aquellos con experiencia legislativa antes que candidatos sin experiencia, sin embargo, tal parece que las preferencias de los partidos en México están más relacionadas con el arrastre electoral, la militancia y sus antecedentes como funcionario público antes que la carrera legislativa de sus postulados. Esta situación se refleja en los requisitos establecidos por las reglas internas de los partidos para elegir a sus candidatos.

En suma, se puede afirmar que si bien la mayoría de los legisladores mexicanos son políticos profesionales, no obstante no todos ejercen una carrera legislativa que profesionalice la actividad parlamentaria. La expectativa es que, con la integración de la reelección consecutiva de los cargos de representación parlamentaria y presidentes municipales, en la reforma constitucional de 2014, se favorezca la institucionalización, profesionalización y rendición de cuentas de los representantes mexicanos. Solo falta 
Artigo | Institucionalización del Congreso Federal Mexicano. Transición democrática y cambio organizacional (ESCAMILLA, Laura Valencia)

observar los años por venir para identificar las ambiciones de los congresistas; si estas continúan siendo ascendentes a pesar de la permisibilidad de la ley para con la reelección o el incentivo de ésta, ofrece la oportunidad de carreras estables que coadyuven a la formación de un sistema político consolidado.

\section{Conclusiones}

La experiencia mexicana respecto a la institucionalización de su poder legislativo se vislumbra como un proceso largo, pero en constante cambio, no siempre continuo y constante, dado que este ha ido de la mano del proceso de transición democrática caracterizado por ser un proceso político-electoral, cuyos cambios han dependido en gran medida del dominio partidista. Como se pudo constatar al descomprimir el sistema autoritario, este no dejó de ser un jugador importante en el proceso de transformación, situación que permitió la construcción lenta de reformas de corto alcance, lo que le dio la posibilidad al Partido Revolucionario Institucional de controlar la conversión hasta las elecciones de 2018 cuando la derrota del PRI es contundente. Del lado contrario, la oposición no ha sido lo suficientemente atrayente para el electorado. El ascenso de la derecha lejos de consolidar el proceso democrático, tuvo muchos problemas para controlar la agenda de transición lo que terminó fragmentándolos. La izquierda por su parte, se contrajo ante sus problemas de división interna por el control del partido y la lucha entre la institucionalización del PRD o la configuración de un liderazgo que eclipsó el desarrollo del partido.

Este contexto produjo cambios variados en los distintos elementos de la institucionalización, si bien la autonomía incrementa su posición, esta no supuso cambios en el sistema presidencial, sino en la composición del congreso, situación que originó inestabilidad en los cambios. Las estructuras normativas e institucionales fueron las mejor dotadas en el proceso de transformación, salvo en el ámbito presupuestal por la falta de transparencia en algunos espacios financieros. La profesionalización política y administrativa de los legisladores mejoró los procesos de la función pública del Congreso, sin embargo, estos progresos fueron limitados da la discrecionalidad de los legisladores para la selección del personal del Congreso. 
Artigo | Institucionalización del Congreso Federal Mexicano. Transición democrática y cambio organizacional (ESCAMILLA, Laura Valencia)

Por lo que toca al control ciudadano y la participación de este, no obstante, la inclusión de mecanismos de participación en la reforma electoral de 2014, como la iniciativa popular, ésta aún requiere del filtro partidista para hacer posible la concreción de propuestas provenientes de la ciudadanía. Finalmente, el control ciudadano mediante la transparencia no fue del todo exitoso, porque si bien es cierto, se mejoraron los servicios para el trabajo legislativo, la información aún es insuficiente en lo que corresponde al manejo de recursos públicos de parte de los legisladores.

\section{Referências}

BÉJAR Algazi, Luisa. "El marco Institucional de la disciplina parlamentaria en México", en Manuel Alcántara (ed) Política en América Latina. I. Congreso Latinoamericano de Ciencia Política. Salamanca: Ediciones Universidad de Salamanca, 2001.

CABRERA Pantoja, Bárbara Leonor. "El papel de los institutos y centros de investigación legislativa en tópicos de coyuntura" ponencia presentada en el Congreso REDIPAL virtual X, México: Cámara de Diputados, 2017.

CÁMARA DE DIPUTADOS. Servicio de Información para la estadística parlamentaria 2020 disponible en

http://sitl.diputados.gob.mx/LXIV leg/listado diputados gpnp.php?tipot=TOTAL consultado el 18 de febrero de 2020.

CAMPOS Vargas Emma. "Un congreso sin congresistas. La no-reelección consecutiva en el poder legislativo mexicano, 1934-1997", en Dworak, Fernando (coord.) El legislador a examen. El Debate sobre reelección legislativa en México, México: FCE/Cámara de Diputados, 2003.

CANCINO, César. El desafío democrático: la transformación del Estado en el México postautoritario México: Centro de Estudios de Política Comparada, AC, 2004.

CASTELLANOS Cereceda, Roberto. La Reforma Político Electoral de 2014. Diagnóstico, primeros resultados y principales desafíos, México: Instituto Belisario Domínguez/Senado de la República, 2016.

CASPER, Gretschen. "Los beneficios de las transiciones difíciles", en Ortega Ortiz, Reynaldo (editor) Caminos a la Democracia, México, El Colegio de México, 2001.

CESOP. Cuadro comparativo internacional sobre los centros de información y análisis parlamentarios, México: Cámara de diputados, 2004.

COLOMER, Josep. Instituciones políticas, Barcelona: Ariel, 2001.

CONSTITUCIÓN DE LOS ESTADOS UNIDOS MEXICANOS, 2020. 
Artigo | Institucionalización del Congreso Federal Mexicano. Transición democrática y cambio organizacional (ESCAMILLA, Laura Valencia)

DAHL, Robert. La democracia. Una guía para los ciudadanos, México: Taurus, 2006.

DE ANDREA Sánchez, Francisco José. "Reelección legislativa consecutiva: una iniciativa de reforma riesgosa", en Boletín Mexicano de Derecho Comparado, núm. 103: México, UNAM, p. 295-305, 2002.

DÍAZ, Héctor. "Los servicios de información y asesoría en el Poder Legislativo mexicano: una reforma pendiente", en Germán Pérez y Antonia Martínez (comps.), La Cámara de Diputados en México, México: FLACSO-Miguel Ángel Porrúa-Cámara de Diputados, 2000.

ELIZONDO Mayer-Serra, Carlos y NACIF Hernández, Benito (compiladores). "La lógica del cambio político en México", en Lecturas sobre el cambio político en México, México: CIDE/FCE, 2002.

ESCAMILLA Cadena, Alberto. "Gobierno de coalición y ratificación del gabinete presidencial", en Miguel González Madrid y Alberto Escamilla (coords.) El nuevo sistema político electoral mexicano en 2015, México: UAM-Iztapalapa, 2015.

ESPEJEL Espinoza, Alberto. "Fases del fraccionalismo. El caso del Partido de la Revolución Democrática", en Estudios Políticos, núm. 26: México: UNAM, 105-129, 2012.

GARCÍA Morillo, Joaquín. "Mitos y realidades del parlamentarismo" en Revista del Centro de Estudios Constitucionales. núm. 9, Madrid, p. 115-144, 1991.

HUNTINGTON, Samuel. "La tercera ola de la democracia", en DIAMOND y PLATTER (compiladores) El resurgimiento de la democracia en sus textos. México: Instituto de Investigaciones Sociales (IIS) UNAM, 1996.

ILLADES, Carlos. "La izquierda populista mexicana" en Nexos: México, 1ㅇ de septiembre, 2016.

INTEGRALIA. Reporte Legislativo. número 4, México: 2012.

JIMÉNEZ Badillo, Margarita. La oposición parlamentara en México. Su rendimiento en gobiernos de mayoría dividida. México: Cámara de Diputados; Miguel Ángel Porrúa, UNAM, 2006.

LAAKSO, M. y TAAGEPERA, R. "Effective Number of Parties: A Measure with Application to West Europe". Comparative Political Studies 12: p. 3-27, 1979.

LEGISLATINA. Observatorio del Poder Legislativo en América Latina Universidad de Salamanca. $2020 . \quad$ Disponible en http://americo.usal.es/oir/legislatina/reeleccion.htm Consultado el 12 de marzo de 2020.

LEY ORGÁNICA DEL CONGRESO GENERAL DE LOS ESTADOS UNIDOS MEXICANOS, 2018.

LINZ, Juan. "Los problemas de las democracias y la diversidad de las democracias", en Rafael de ÁGUILA, Fernando VALLESPín, et. al. La democracia en sus textos. Madrid: Alianza, 1988. 
Artigo | Institucionalización del Congreso Federal Mexicano. Transición democrática y cambio organizacional (ESCAMILLA, Laura Valencia)

MAGALONI, Beatriz. "Voting for Autocracy: Hegemonic Party Survival and its Demise in Mexico" en Cambridge University Press. 2006. Disponible en http://www.sscnet.ucla.edu/polisci/cpworkshop/papers/Magaloni.pdf, consultado el 23 de enero de 2020.

MÁRQUEZ Rosales, Antonio y TOVAR Partida, Guillermo. "Reformas Anticorrupción en México: Introducción a la ley de fiscalización y rendición de cuentas de a federación" en Revista Iberoamericana de Contaduría, Economía y Administración. v. 7, núm. 14. México: p. 1-32, 2018.

MERINO, Mauricio. La transición votada. Crítica a la interpretación del cambio político en México. México: F.C.E. 2003.

MOLINAR Horcasitas, Juan. "Counting the number of parties: an alternative index", en American Political Science Review, vol 85, núm 4, p. 1383-1391. 1991.

MORLINO, Leonardo. Democracy Between Consolidation and Crisis: Parties, Groups, and Citizens in Southern Europe. Oxford: Oxford University Press, 1998.

OPENING PARLIAMENT.ORG Declaración sobre la transparencia parlamentaria. 2012. Disponible en http://openingparliament.org/static/pdfs/spanish.pdf Consultado el 14 de abril de 2019.

RED LATINOAMERICANA POR LA TRANSPARENCIA LEGISLATIVA Índice Latinoamericano de transparencia legislativa. 2014. Disponible en http://www.transparencialegislativa.org/wp-content/uploads/2014/09/ÍndiceLatinoamericano-de-Transparencia-Legislativa-2014.pdf consultado el 6 de marzo de 2019.

Índice Latinoamericano de transparencia legislativa. 2018.

Disponible en

https://docs.wixstatic.com/ugd/81fb17 a66f366460344e18bb218f6e93b39879.pdf Consultado el 15 de mayo de 2019.

RENIU Vilamala, Josep M. "Los gobiernos de coalición en los sistemas presidenciales de Latinoamérica: elementos para el debate" en $C I D O B$, número 25: Barcelona, 2008.

RUBIO, Luis. "El poder legislativo un contrapeso", en Crónica Legislativa. México: Cámara de Diputados, 2005.

SAIEGH, Sebastián. "Active players or rubber stamps? An evaluation of the policymaking role of Latin American legislatures", en Scartascini, Stein y Tommasi, (editors) How democracy Works. Political institution, actors, arenas in Latin American policy making, New York: BID, 2010.

SÁNCHEZ Rebolledo, Adolfo y TREJO Delabre, Bertha. Quién es quién en el Congreso. LVII y LVIII legislatura 1997-2003. México: Instituto de Estudios de la Transición Democrática, México, 2012.

SECRETARÍA DE GOBERNACIÓN. Sistema de Información Legislativa 2020 en línea http://sil.gobernacion.gob.mx/portal consultado el 13 de febrero de 2020. 
Artigo | Institucionalización del Congreso Federal Mexicano. Transición democrática y cambio organizacional (ESCAMILLA, Laura Valencia)

SERVICIO DE INFORMACIÓN PARA LA ESTADÍSTICA PARLAMENTARIA (INFOPAL) LVII-LXIV Legislaturas, Cámara de Diputados. 2020. Disponible en: http://www.diputados.gob.mx/sistema legislativo.html Consultado el 18 de enero de 2020.

TRANSPARENCIA A.C. Buenas Prácticas Parlamentarias en América Latina, Lima: Transparencia A.C, 2013.

UNIÓN INTERPARLAMENTARIA. Informe Parlamentario Mundial. La naturaleza Cambiante de la Representación Parlamentaria, Dinamarca: PNUD/Unión Interparlamentaria, 2012.

VALENCIA Escamilla, Laura "Equilibrio de poderes, cooperación y la conformación de gobiernos de coalición en México", Revista Legislativa de Estudios Sociales y de Opinión Pública. vol.6, num. 11, México: Cámara de Diputados, p. 7-44, 2013.

La representación parlamentaria. Un recorrido histórico por la teoría política. México: Siglo XXI/Cámara de Senadores, 2016.

"Representación parlamentaria, ciudadanía y rendición de cuentas vertical", en Apuntes Electorales. núm. 58, México: IEEM, p. 61-96, 2018.

VIRGALA Foruria, Eduardo. "La forma de gobierno semiparlamentaria como alternativa a la presidencial y a la parlamentaria", en Revista de Estudios Políticos. núm. 89, p. 119-164, 1995. 